OPEN ACCESS

Edited by:

Guo-Ping Shi,

Brigham and Women's Hospital and Harvard Medical School,

United States

Reviewed by:

Peter William Gunning,

University of New South Wales,

Australia

Zhaojie Meng,

Brigham and Women's Hospital and Harvard Medical School,

United States

*Correspondence:

Maciej Gagat

mgagat@cm.umk.pl

†These authors have contributed equally to this work

FThese authors share senior authorship

Specialty section:

This article was submitted to

Signaling,

a section of the journa

Frontiers in Cell and Developmental

Biology

Received: 15 February 2021

Accepted: 25 August 2021

Published: 17 September 2021

Citation:

Gagat M, Zielińska W,

Mikołajczyk K, Zabrzyński J,

Krajewski A,

Klimaszewska-Wiśniewska A, Grzanka D and Grzanka A (2021)

CRISPR-Based Activation

of Endogenous Expression of TPM1

Inhibits Inflammatory Response

of Primary Human Coronary Artery

Endothelial and Smooth Muscle Cells Induced by Recombinant Human

Tumor Necrosis Factor $\alpha$.

Front. Cell Dev. Biol. 9:668032. doi: 10.3389/fcell.2021.668032

\section{CRISPR-Based Activation of} Endogenous Expression of TPM1 Inhibits Inflammatory Response of Primary Human Coronary Artery Endothelial and Smooth Muscle Cells Induced by Recombinant Human Tumor Necrosis Factor $\alpha$

\author{
Maciej Gagat ${ }^{1 *}$, Wioletta Zielińska ${ }^{1 \dagger}$, Klaudia Mikołajczyk ${ }^{1 \dagger}$, Jan Zabrzyński ${ }^{2,3}$, \\ Adrian Krajewski ${ }^{1}$, Anna Klimaszewska-Wiśniewska ${ }^{2}$, Dariusz Grzanka² and \\ Alina Grzanka ${ }^{1 \neq}$ \\ 1 Department of Histology and Embryology, Faculty of Medicine, Nicolaus Copernicus University in Toruń, Collegium \\ Medicum in Bydgoszcz, Bydgoszcz, Poland, ${ }^{2}$ Department of Clinical Pathomorphology, Faculty of Medicine, Nicolaus \\ Copernicus University in Toruń, Collegium Medicum in Bydgoszcz, Bydgoszcz, Poland, ${ }^{3}$ Department of General \\ Orthopaedics, Musculoskeletal Oncology and Trauma Surgery, University of Medical Sciences, Poznań, Poland
}

Tumor necrosis factor $\alpha(T N F \alpha)$ is one of the most important proinflammatory cytokines, which affects many processes associated with the growth and characteristics of endothelial, smooth muscle, and immune system cells. However, there is no correlation between most in vivo and in vitro studies on its role in endothelial cell proliferation and migration. In this study, we examined the effect of recombinant human (rh) TNF $\alpha$ produced in HEK293 cells on primary human coronary artery endothelial cells (pHCAECs) in the context of F-actin organization and such processes as migration and adhesion. Furthermore, we evaluated the possibility of the inhibition of the endothelial inflammatory response by the CRISPR-based regulation of TPM1 gene expression. We showed that TNF $\alpha$-induced activation of pHCAECs was related to the reorganization of the actin cytoskeleton into parallel-arranged stress fibers running along the longer axis of pHCAECs. It allowed for the directed and parallel motion of the cells during coordinated migration. This change in F-actin organization promoted strong but discontinuous cell-cell contacts involved in signalization between migrating cells. Moreover, this form of intercellular connections together with locally increased adhesion was related to the formation of migrasomes and further migracytosis. Stabilization of the actin cytoskeleton through the CRISPR-based activation of endogenous expression of TPM1 resulted in the inhibition of the inflammatory response of pHCAECs following treatment with rh TNF $\alpha$ and stabilization of cell-cell junctions through reduced cleavage of vascular endothelial cadherin (VE-cadherin) and maintenance of the stable levels of 
$\alpha$ - and $\beta$-catenins. We also showed that CRISPR-based activation of TPM1 reduced inflammatory activation, proliferation, and migration of primary human coronary artery smooth muscle cells. Therefore, products of the TPM1 gene may be a potential therapeutic target for the treatment of proinflammatory vascular disorders.

Keywords: TNF $\alpha$, endothelial cells, angiogenesis, F-actin, cell-cell junctions, cell adhesion, migrasomes, inflammation

\section{INTRODUCTION}

The endothelial barrier plays a pivotal role in the regulation of the functioning of the entire circulatory system (Godo and Shimokawa, 2017). For this reason, any disturbances in the endothelial structure are associated with unfavorable health effects. Endothelial dysfunction manifests into abnormalities in the anticoagulant and anti-inflammatory properties of cells as well as alterations in vascular growth and vascular remodeling. It is associated with phenomena like hypertension and atherosclerosis (Chistiakov et al., 2015; Gimbrone and García-Cardeña, 2016). Endothelium produces nitric oxide, which is responsible for the relaxation of the underlying vascular smooth muscle. Reduced activity of endothelial nitric oxide synthase is observed in diabetes and hypertension. It also promotes vasoconstriction, thrombosis, and infiltration of the immune system cells (Matsushita et al., 2001). In turn, it is associated with the increased production of proinflammatory factors that induce the excessive proliferation of vascular smooth muscle cells. Proinflammatory cytokines also cause further accumulation of immune cells at the site of endothelial layer disruption. The increased production of endothelium-derived contracting factors leads to even greater deregulation of vessel wall functioning (Virdis et al., 2010).

Disbalance between the vasodilators and vasoconstrictors is not the only phenomenon leading to disruption of the endothelial barrier. From a biological perspective, endothelial dysfunction begins much earlier and manifests by intense changes in the structure, level, and function of membrane and intracellular proteins (Gimbrone and García-Cardeña, 2016). They are associated particularly with abnormalities at the level of junctional proteins, which can be observed as alterations in the pattern of intercellular connections. The types of cell contacts that guarantee the continuity of the endothelial layer are adherens junctions (AJs) and tight junctions (TJs). The main proteins involved in those types of connections in vascular endothelium are vascular endothelial cadherin (VE-cadherin) and claudin5. However, proinflammatory conditions lead to a loosening of the junctional network, which manifests in the discontinuity at the cell-cell border and the appearance of spaces between cells (Cerutti and Ridley, 2017). These spaces allow, for example, massive infiltration of monocytes to the vessel wall, observed during the development and exacerbation of atherosclerosis. Other effects of proinflammatory conditions are enhanced cell adhesion and increased migration (Kaczmarek et al., 2005; Perna et al., 2013). In our work, we suggest that increased intracellular tensions result in the mechanistic disruption of intercellular junctions, which leads to the loss of the endothelial barrier continuity.
Endothelial injury, as well as angiogenesis, propels the migration of endothelial cells, which aims to restore the continuity of the endothelial monolayer or formation of new vessels (Michaelis, 2014). The cells can migrate both individually and in a coordinated manner depending on the intercellular signals and environmental factors. Collective migration is defined as the migration of cells that remain functionally and physically connected through stable intercellular connections. At the same time, such cells are characterized by multicellular polarity and the organization of the cytoskeleton that allows them to generate traction forces. In this type of migration, cell movement is coordinated locally and as a result, tightly connected cells move in the same direction (Canver et al., 2016).

All these changes, however, would not be possible without alterations at the actin cytoskeleton level. Changes in the organization of F-actin are involved in such processes as migration, proliferation, and cell adhesion. Moreover, the interaction of the actin cytoskeleton with junctional proteins allows the transfer of tensions from the relatively weak intercellular junctions to the more resistant cytoskeleton (van Geemen et al., 2014). In the case of non-activated endothelium, F-actin is organized into characteristic star-like structures that guarantee an appropriate distribution of intracellular tensions and enable a quick response to external factors, for example, through the ability of multidirectional migration. However, cell activation in response to proinflammatory cytokines involves the remodeling of the actin network into thick bundles of highly polymerized and parallel stress fibers. The changes in the organization of the actin cytoskeleton are possible only due to the activity of actin-binding proteins, which include tropomyosins (Gunning et al., 2015).

We have shown that tropomyosin-1 inhibits both polymerization and depolymerization of the actin filaments induced by L-homocysteine and cigarette smoke extract and impacts the integrity of EA.hy926 endothelial cells (Gagat et al., 2013, 2014). However, whether and how the expression of tropomyosin-1 and stabilization of actin cytoskeleton affect the inflammatory response of endothelial cells remain unknown. Therefore, the main goal of this study is to show that CRISPR-based activation of TPM1 expression can maintain the proper organization of coronary artery endothelial cell monolayer and inhibit proliferation of smooth muscle cells in inflammatory conditions mimicked by the use of human recombinant (rh) tumor necrosis factor $\alpha(\mathrm{TNF} \alpha)$. In the present study, we characterized the effect of rh TNF $\alpha$ on primary human coronary artery endothelial cells (pHCAECs) in the context of F-actin organization and modulation of F-actin-dependent processes, including cell migration, adhesion, and migracytosis. The obtained results are important not 
only from the mechanistic point of view but also have the potential to be translated into clinical research and adapted during the design and development of new coronary stent devices.

\section{MATERIALS AND METHODS}

\section{Cell Culture and Treatment}

Primary human coronary artery endothelial cells and primary human coronary artery smooth muscle cells (pHCASMCs) were obtained from a healthy 23-year-old white male or 53-year-old white male, respectively (cause of death: head trauma secondary to blunt injury). The cells were provided by the American Type Culture Collection (ATCC) and maintained according to supplier recommendations. Briefly, the endothelial cells were cultured in a vascular cell basal medium (ATCC) supplemented with an endothelial cell growth kit (ATCC) containing $5 \mathrm{ng} / \mathrm{ml}$ recombinant human (rh) VEGF, $5 \mathrm{ng} / \mathrm{ml} \mathrm{rh} \mathrm{EGF,} 5 \mathrm{ng} / \mathrm{ml} \mathrm{rh}$ FGF basic, $15 \mathrm{ng} / \mathrm{ml} \mathrm{rh}$ IGF-1, $10 \mathrm{mM}$ L-glutamine, $0.75 \mathrm{units} / \mathrm{ml}$ heparin sulfate, $1 \mu \mathrm{g} / \mathrm{ml}$ hydrocortisone hemisuccinate, $2 \%$ fetal bovine serum (FBS), $50 \mu \mathrm{g} / \mathrm{ml}$ ascorbic acid, and antibiotics (10 units/ml penicillin, $10 \mu \mathrm{g} / \mathrm{ml}$ streptomycin, and $25 \mu \mathrm{g} / \mathrm{ml}$ amphotericin B). The smooth muscle cells were cultured in a vascular cell basal medium (ATCC) supplemented with a vascular smooth muscle cell growth kit (ATCC) containing $5 \mathrm{ng} / \mathrm{ml} \mathrm{rh}$ FGF-basic, $5 \mu \mathrm{g} / \mathrm{ml} \mathrm{rh}$ insulin, $50 \mu \mathrm{g} / \mathrm{ml}$ ascorbic acid, $10 \mathrm{mM} \mathrm{L-}$ glutamine, $5 \mathrm{ng} / \mathrm{ml} \mathrm{rh}$ EGF, $5 \%$ fetal bovine serum, and antibiotics (10 units $/ \mathrm{ml}$ penicillin, $10 \mu \mathrm{g} / \mathrm{ml}$ streptomycin, and $25 \mu \mathrm{g} / \mathrm{ml}$ amphotericin B). The cells were initially seeded at a density of 5,000 viable cells $/ \mathrm{cm}^{2}$ and cultured in T-25 $\mathrm{cm}^{2}$ flasks (Corning) at $37^{\circ} \mathrm{C}$ in a humidified atmosphere of $5 \% \mathrm{CO}_{2}$ and $95 \%$ air. After reaching confluence, the cells were treated with complete vascular growth medium containing rh TNF $\alpha$ (Sigma-Aldrich), expressed in HEK293 cells, at a concentration of $100 \mathrm{ng} / \mathrm{ml}$ for $24 \mathrm{~h}$ (or $36 \mathrm{~h}$ for time-dependent analysis of migration directiveness). The control cells were grown under the same condition without rh $\mathrm{TNF} \alpha$ treatment. Only cells within three to four passages were used for all the experiments.

\section{Detection of Functional Expression of Adhesion Molecules}

The detection of functional expression of E-selectin and VCAM1 was performed using antibody-coated magnetic beads. The immobilization of Dynabeads M-280 Sheep Anti-Mouse IgG (Thermo Fisher Scientific) was done according to manufacturer instructions. Briefly, $2 \mu \mathrm{g}$ of mouse anti-E-selectin (clone: CL2/6) or mouse anti-VCAM-1 (clone: 1.G11B1) monoclonal antibodies (both from Thermo Fisher Scientific) was added to $50 \mu \mathrm{l}$ of pre-washed beads and resuspended in $1 \mathrm{ml}$ of $\mathrm{Ca}^{2+}$ - and $\mathrm{Mg}^{2+}$ free phosphate-buffered saline (PBS, $\mathrm{pH} 7.4$ ), supplemented with $0.1 \%$ bovine serum albumin (BSA, Sigma-Aldrich) and $2 \mathrm{mM}$ EDTA (Sigma-Aldrich), and incubated with gentle tilting and rotation for $18 \mathrm{~h}$ at $4^{\circ} \mathrm{C}$. The beads were then washed four times using a washing buffer and resuspended in $1 \mathrm{ml}$ of complete and pre-warmed vascular growth medium. Five hundred microliters of resuspended beads was added to $100 \mathrm{ng} / \mathrm{ml} \mathrm{TNF} \alpha$-treated or control pHCAECs grown in 24-well glass-bottom cell imaging plates (Eppendorf) and incubated in standard cell culture conditions for $30 \mathrm{~min}$. After washing with Dulbecco's PBS (DPBS, ATCC), the cells were fixed in 4\% paraformaldehyde in PBS for $20 \mathrm{~min}$ (Sigma-Aldrich) and stained for F-actin using Alexa Fluor 594 phalloidin (Thermo Fisher Scientific) for $20 \mathrm{~min}$. The cells were then counterstained with 4',6-diamidino-2-phenylindole (DAPI, Sigma-Aldrich) for $10 \mathrm{~min}$. All steps were performed at room temperature (RT). Images were acquired on an Axio Observer Z1 inverted motorized microscope (Zeiss), using an EC Plan-Neofluar $\times$ 10/0.30 Ph1 air objective, Axiocam 503 mono camera, and ZEN 2 software (all from Zeiss). Parallel bright-field and fluorescence images were recorded at the same location.

\section{Co-culture of Primary Human Coronary Artery Endothelial Cells With Jurkat T Cells}

Jurkat T cells (clone E6-1, ATCC) were maintained according to supplier recommendations. Briefly, the cells were initially seeded at a density of $1 \times 10^{5}$ viable cells $/ \mathrm{ml}$ and maintained in RPMI-1640 medium supplemented with $10 \%$ FBS and $50 \mu \mathrm{g} / \mathrm{ml}$ gentamycin (all from Lonza) in T-25 $\mathrm{cm}^{2}$ flasks (Corning) at $37^{\circ} \mathrm{C}$ in a humidified atmosphere of $5 \% \mathrm{CO}_{2}$ and $95 \%$ air. After the desired density is reached, the cells were stimulated with $100 \mathrm{ng} / \mathrm{ml} \mathrm{rh} \mathrm{TNF} \alpha$ for $2 \mathrm{~h}$. The nuclei of cells were stained using the NucBlue Live Cell Stain ReadyProbes Reagent (Hoechst 33342 dye, Thermo Fisher Scientific) for $30 \mathrm{~min}$. Around $2 \times 10^{5}$ counterstained Jurkat $\mathrm{T}$ cells were then washed with DPBS, resuspended in $500 \mu \mathrm{l}$ of complete and prewarmed vascular growth medium and added to TNF $\alpha$-activated or control pHCAECs grown in 12-well plates (Corning). Jurkat $\mathrm{T}$ cells were co-cultured with pHCAECs in standard cell culture conditions for $30 \mathrm{~min}$ in the presence or absence of rh TNF $\alpha$. Before co-culture, pHCAECs were cultured in the presence or absence of $\mathrm{rh} \mathrm{TNF} \alpha$ for $24 \mathrm{~h}$. Time-lapse images were acquired, at 3.33-s intervals over $2 \mathrm{~min}$, in standard cell culture conditions on an Axio Observer Z1 inverted motorized microscope (Zeiss) equipped with an incubation system for livecell imaging (PeCon), using an EC Plan-Neofluar $\times 10 / 0.30$ Ph1 air objective, Axiocam 503 mono camera, and ZEN 2 software (all from Zeiss). Parallel contrast phase and fluorescence images were recorded at the same location. The number of adherent Jurkat $\mathrm{T}$ cells was counted after washing cells three times with DPBS in three randomly chosen microscopic fields using Image (NIH).

\section{Confluent Cell Migration}

Confluent cell migration assay was performed using six-well plates (Corning). After confluence is reached, the cells were cultured in complete vascular growth medium supplemented or not with $100 \mathrm{ng} / \mathrm{ml} \mathrm{rh} \mathrm{TNF} \alpha$. Time-lapse images were acquired, at 10 -min intervals over $36 \mathrm{~h}$ in standard cell culture conditions on an Axio Observer Z1 inverted motorized microscope (Zeiss) equipped with an incubation system for live-cell imaging (PeCon), using an EC Plan-Neofluar $\times 10 / 0.30 \mathrm{Ph} 1$ air objective, Axiocam 503 mono camera, and ZEN 2 software (all from 
Zeiss). Phase contrast images were recorded at a location of the migration gap and sites of open-field migration. Cell movement was analyzed using the Manual Tracking plugin for ImageJ (NIH). To quantify the dynamics of cell migration, such as velocity or Euclidean distance and accumulated distance, the migration trajectories were then assessed with Chemotaxis and Migration Tool 2.0 (Ibidi).

\section{Wound Healing and Open-Field Migration}

Wound healing and open-field migration assays were performed using a two-well culture insert (Ibidi). pHCAECs were resuspended in $70 \mu \mathrm{l}$ of complete vascular growth medium and plated at a density of 1,100 cells per well into each reservoir of a culture insert (Ibidi) that adhered to the bottom of a six-well plate (Corning) and grown in standard cell culture conditions. After confluence is reached, the insert was removed using forceps, and the plate was rinsed with DPBS to remove cell debris. Migrating cells were cultured in complete vascular growth medium supplemented or not with $100 \mathrm{ng} / \mathrm{ml} \mathrm{rh}$ TNF $\alpha$. Time-lapse images were acquired, at 10-min intervals over $24 \mathrm{~h}$, in standard cell culture conditions on an Axio Observer Z1 inverted motorized microscope (Zeiss) equipped with an incubation system for live-cell imaging (PeCon), using an EC Plan-Neofluar $\times 10 / 0.30 \mathrm{Ph} 1$ air objective, Axiocam 503 mono camera, and ZEN 2 software (all from Zeiss). Phase contrast images were recorded at a location of the migration gap and sites of open-field migration. Cell movement was analyzed using the Manual Tracking plugin for ImageJ (NIH). To quantify the dynamics of cell migration, such as velocity or Euclidean distance and accumulated distance, the migration trajectories were then assessed with Chemotaxis and Migration Tool 2.0 (Ibidi).

\section{Modified Boyden Chamber Assay}

Modified Boyden chamber assay was done using uncoated Transwell inserts with microporous polyethylene terephthalate (PET) membranes (3- $\mu \mathrm{m}$ pore size) placed in 24 -well plates (both from Corning). pHCAECs were resuspended at a density of 1,650 cells per well in complete vascular growth medium and plated in the upper chamber of the Transwell inserts. The lower chamber of the wells contained $600 \mu \mathrm{l}$ of complete vascular growth medium. After confluence is reached, the media in the upper Transwell chamber were replaced with complete vascular growth medium supplemented or not with $100 \mathrm{ng} / \mathrm{ml} \mathrm{rh} \mathrm{TNF} \alpha$. The media in the wells of the 24-well plate were the same and additionally supplemented with 20\% FBS. After 24 h, the Transwell inserts were fixed with $4 \%$ formaldehyde for $15 \mathrm{~min}$ (Sigma-Aldrich) and washed three times with PBS, and the cells were stained with toluidine blue. All steps were performed at RT. The cells on the upper side of the membrane were removed with cotton swabs, and the inserts were left to air-dry. Bright-field images of the lower side of the membranes were captured by an Eclipse E800 microscope (Nikon) using a Plan Fluor $\times 10 / 0.30$ air objective, DS-5Mc-U1 camera, and NIS-Elements 3.30 (all from Nikon). The number of migrated cells was counted in randomly chosen microscopic fields using Image $(\mathrm{NIH})$.

\section{In vitro Tube Formation Assay}

Endothelial tube formation assay was performed in $\mu$-Slide Angiogenesis (Ibidi) according to the manufacturer's guidelines. Briefly, inner wells were filled with $10 \mu \mathrm{l}$ of ice-cold, growth factor-reduced, and phenol-red-free Matrigel Basement Membrane Matrix (Corning) and set at $37^{\circ} \mathrm{C}$. pHCAECs were resuspended in $50 \mu \mathrm{l}$ of complete vascular growth medium supplemented or not with $100 \mathrm{ng} / \mathrm{ml} \mathrm{rh} \mathrm{TNF} \alpha$ and plated at a density of 10,000 cells per well into the upper well and cultured in standard conditions. Time-lapse images were acquired, at 10-min intervals over $24 \mathrm{~h}$, in standard cell culture conditions on an Axio Observer Z1 inverted motorized microscope (Zeiss) equipped with an incubation system for live-cell imaging (PeCon), using a Zeiss EC Plan-Neofluar $\times 10 / 0.30$ Ph1 air objective, Axiocam 503 mono camera, and ZEN 2 software (all from Zeiss). Contrast phase images were recorded at the same location. Additionally, tube formation was monitored using a bright-field microscope at $3,6,12$, and $24 \mathrm{~h}$ after seeding. The cells were fixed with $4 \%$ formaldehyde for $15 \mathrm{~min}$ (Sigma-Aldrich), washed three times with PBS, and stained with crystal violet. All steps were performed at RT. Bright-field images were captured by an Eclipse E800 microscope (Nikon) using a Plan UW $\times 2 / 0.06$ air objective, DS-5Mc-U1 camera, and NIS-Elements 3.30 (all from Nikon). The number of tubes was counted using ImageJ (NIH).

\section{Wash Assay}

Wash assay was performed using six-well plates (Corning). The cells were initially seeded at a density of 5,000 viable cells $/ \mathrm{cm}^{2}$ in complete vascular growth medium supplemented or not with $100 \mathrm{ng} / \mathrm{ml} \mathrm{rh} \mathrm{TNF} \alpha$ and cultured in a humidified atmosphere of $5 \% \mathrm{CO}_{2}$ and $95 \%$ air. At $0,0.5,2$, and $4 \mathrm{~h}$ after seeding, the cells were washed three times with complete vascular growth to remove non-adherent cells. Contrast phase images were captured in standard cell culture conditions on an Axio Observer Z1 inverted motorized microscope (Zeiss) equipped with an incubation system for live-cell imaging (PeCon), using a Zeiss EC Plan-Neofluar $\times$ 10/0.30 Ph1 air objective, Axiocam 503 mono camera, and ZEN 2 software (all from Zeiss). The number of adherent cells was counted using Image (NIH).

\section{Temporal Analysis of Actin Cytoskeleton and Focal Adhesion Sites}

For temporal analysis of $\mathrm{TNF} \alpha$-induced changes in the organization of actin cytoskeleton and actin-mediated focal adhesion, pHCAECs were transiently transduced using a baculovirus system to express the green fluorescent protein (GFP)-fused human actin and the red fluorescent protein (RFP) fused to the c-terminus of human talin. The cells were transiently transduced with CellLight Reagents BacMam 2.0 (Thermo Fisher Scientific) according to the manufacturer's recommendations. Briefly, pHCAECs were grown in 24-well cell imaging plates (Eppendorf) and cultured in standard conditions. After 70\% confluence is reached, the cells were infected with CellLight actinGFP and CellLight Talin-RFP BacMam 2.0 baculoviruses at a multiplicity of infection (MOI) of 30 . After $16 \mathrm{~h}$, the medium containing the baculoviruses was replaced with complete vascular 
growth medium supplemented or not with $100 \mathrm{ng} / \mathrm{ml} \mathrm{rh} \mathrm{TNF} \alpha$, and the cells were cultured in standard conditions. Timelapse images were acquired, at 10-min intervals over $24 \mathrm{~h}$, in standard cell culture conditions on an Axio Observer Z1 inverted motorized microscope (Zeiss) equipped with an incubation system for live-cell imaging (PeCon), using a Zeiss EC PlanNeofluar $\times 10 / 0.30$ Ph1 air objective, Axiocam 503 mono camera, and ZEN 2 software (all from Zeiss). Fluorescence images were recorded at the same location. Furthermore, correlation between 3D morphology and localization of actin-GFP and talin-RFP in rh TNF-activated pHCAECs was imaged using an HT-2 correlative holotomographic and fluorescence microscope (Tomocube). For live-cell correlative holotomographic and fluorescence imaging, the cells were grown in 50-mm imaging dishes with $1.5 \mathrm{H}$ glass coverslip bottom (TomoDish, Tomocube) and covered before imaging with a square coverslip glass. For prevention against contamination and drying of the medium, the side of the dish was sealed by mineral oil (Sigma). Additionally, expression of actin-GFP and talin-RFP was examined by confocal microscopy. The cells were fixed with $4 \%$ formaldehyde for 15 min (SigmaAldrich), washed three times with PBS, and counterstained with DAPI (Sigma-Aldrich) for $10 \mathrm{~min}$. All steps were performed at RT. Images were captured by a $\mathrm{C} 1$ laser scanning confocal microscope (Nikon) using a Plan VC Apo $\times 60 / 1.4$ oil objective and Nikon EZ-C1 3.80 software (both from Nikon). The lasers used for DAPI, GFP, and RFP excitations were diode $408 \mathrm{~nm}$ with emission filter $450 / 35$, diode $488 \mathrm{~nm}$ with emission filter $515 / 30$, and $\mathrm{He}-\mathrm{Ne} 543 \mathrm{~nm}$ with emission filter 650LP, respectively. All confocal images of triple-labeled cells were acquired and displayed with identical settings, including laser power, pixel dwell speed, and gain.

\section{Coating With Extracellular Matrix Proteins}

For the analysis of the possible effect of extracellular matrix (ECM) on different rearrangements of F-actin in TNF $\alpha$-activated pHCAECs, the sterile glass coverslips (? $18 \mathrm{~mm}$, Thermo Fisher Scientific) were covered by $5 \mathrm{~g} / \mathrm{cm}^{2}$ fibronectin (source: human plasma), laminin (source: Engelbreth-Holm-Swarm mouse tumor), collagen I (source: rat tail tendon), and collagen IV (source: Engelbreth-Holm-Swarm mouse tumor; all from Corning) according the manufacturer's instruction. The cells were grown on the coated glass coverslips in 12-well plates (Corning) and cultured in standard conditions. After confluence is reached, the cells were cultured for an additional period of $24 \mathrm{~h}$ in complete vascular growth medium supplemented or not with $100 \mathrm{ng} / \mathrm{ml} \mathrm{rh}$ TNF $\alpha$. The cells were then fixed with $4 \%$ formaldehyde for $15 \mathrm{~min}$ (Sigma-Aldrich), permeabilized for 10 min with $0.25 \%$ Triton X-100 (Serva), blocked with 3\% BSA for $45 \mathrm{~min}$ (Sigma-Aldrich), and stained for F-actin using phalloidin-Alexa Fluor 488 (1:40) and phalloidin-Alexa Fluor 594 (1:40; both from Thermo Fisher Scientific). The cells were then counterstained with DAPI (Sigma-Aldrich) for $10 \mathrm{~min}$. All of the fluorescence reaction steps were performed at RT. The slides were mounted in Aqua-Poly/Mount (Polysciences) and examined by confocal microscopy. Images were captured by a
C1 laser scanning confocal microscope (Nikon) using a Plan VC Apo $\times$ 60/1.4 oil objective and Nikon EZ-C1 3.80 software (both from Nikon).

\section{Transfection by Nucleofection}

Endogenous expression of TPM1 gene was regulated using CRISPR TPM1 activation or knockout systems (both from Santa Cruz). The CRISPR activation system is a synergistic activation mediator transcription activation system designed to specifically upregulate TPM1 and consists of three plasmids at a 1:1:1 mass ratio: a plasmid encoding the deactivated Cas9 nuclease (D10A and N863A) fused to the transactivation domain VP64, a plasmid encoding the MS2-p65-HSF1 fusion protein, and a plasmid encoding a TPM1-specific 20-nt guide RNA. The CRISPR TPM1-knockout system consists of a pool of three plasmids each encoding the Cas9 nuclease and a TPM1-specific 20-nt guide RNA. As a CRISPR control, we used the CRISPR control plasmid encoding the Cas9 nuclease and a non-specific 20-nt guide RNA. Components of the above-mentioned CRISPR systems were delivered into the cells by nucleofection technology according to the manufacturer's instruction using the P5 Primary Cell 4D-Nucleofector X Kit L and 4D-Nucleofector X unit (both from Lonza). Briefly, $4 \times 10^{5}$ cells were resuspended in 100 Nucleofector nucleofection solution and $2 \mu \mathrm{g}$ of each CRISPR system was electroporated using the DY138 program at RT. The cells were then immediately transferred into pre-warmed complete vascular growth medium and cultured until confluency is reached for further procedures.

\section{Fluorescence Localization of Proteins}

For the fluorescence localization of proteins, the pHCAECs were grown on sterile glass coverslips (? $18 \mathrm{~mm}$, Thermo Fisher Scientific) in 12-well plates (Corning) and cultured in standard conditions. After confluence is reached, the cells were cultured for an additional period of $24 \mathrm{~h}$ in complete vascular growth medium supplemented or not with $100 \mathrm{ng} / \mathrm{ml} \mathrm{rh}$ TNF $\alpha$. The cells were then fixed with $4 \%$ formaldehyde for 15 min (Sigma-Aldrich), permeabilized for $10 \mathrm{~min}$ with $0.25 \%$ Triton X-100 (Serva), and blocked with 3\% BSA for 45 min (SigmaAldrich). Next, the cells were double stained using antibodies and phalloidin conjugates in the following arrangement: (i) mouse anti-talin (clone: 8D4) monoclonal antibody (1:500, Sigma-Aldrich), goat anti-mouse-Alexa Fluor 488 secondary antibody (1:200, Thermo Fisher Scientific), and phalloidin-Alexa Fluor 594 (1:40, Thermo Fisher Scientific); (ii) rabbit antiVE-cadherin polyclonal antibody (1:200), donkey anti-rabbitAlexa Fluor 594 secondary antibody (1:200), and phalloidinAlexa Fluor 488 (1:40; all from Thermo Fisher Scientific); (iii) mouse anti- $\alpha$-catenin (clone: 7A4) monoclonal antibody (1:250), goat anti-mouse-Alexa Fluor 488 secondary antibody (1:200), and phalloidin-Alexa Fluor 594 (1:40; all from Thermo Fisher Scientific); (iv) mouse anti- $\beta$-catenin (clone: $5 \mathrm{H} 10)$ monoclonal antibody (1:250), goat anti-mouse-Alexa Fluor 488 secondary antibody (1:200), and phalloidin-Alexa Fluor 594 (1:40; all from Thermo Fisher Scientific); (v) mouse anti-ZO-1 (clone: 1A12) monoclonal antibody (1:200), goat anti-mouse-Alexa Fluor 488 secondary antibody (1:200), and phalloidin-Alexa Fluor 594 
(1:40; all from Thermo Fisher Scientific); (vi) mouse anti-claudin5 (clone: 4C3C2) monoclonal antibody (1:300), goat anti-mouseAlexa Fluor 488 secondary antibody (1:200), and phalloidinAlexa Fluor 594 (1:40; all from Thermo Fisher Scientific); (vii) rabbit anti-non-muscle myosin IIa (MYH9) polyclonal antibody (1:100), donkey anti-rabbit-Alexa Fluor 594 secondary antibody (1:200), and phalloidin-Alexa Fluor 488 (1:40; all from Thermo Fisher Scientific); (viii) rabbit anti-non-muscle myosin IIb (MYH10) polyclonal antibody (1:100), donkey anti-rabbitAlexa Fluor 594 secondary antibody (1:200), and phalloidinAlexa Fluor 488 (1:40; all from Thermo Fisher Scientific); (ix) rabbit anti-Arp $2 / 3$ subunit $1 \mathrm{~B}$ (ARPC1B) polyclonal antibody (1:100, Abcam), donkey anti-rabbit-Alexa Fluor 594 secondary antibody (1:200, Thermo Fisher Scientific), and phalloidin-Alexa Fluor 488 (1:40, Thermo Fisher Scientific); (x) rabbit anti-ROCK1 polyclonal antibody (1:100), donkey anti-rabbit-Alexa Fluor 594 secondary antibody (1:200), and phalloidin-Alexa Fluor 488 (1:40; all from Thermo Fisher Scientific); (xi) rabbit antiROCK-2 polyclonal antibody (1:100), donkey anti-rabbit-Alexa Fluor 594 secondary antibody (1:200), and phalloidin-Alexa Fluor 488 (1:40; all from Thermo Fisher Scientific); (xii) mouse anti-E-selectin (clone: CL2/6) monoclonal antibody (1:100), goat anti-mouse-Alexa Fluor 488 secondary antibody (1:200), and phalloidin-Alexa Fluor 594 (1:40; all from Thermo Fisher Scientific); and (xiii) mouse anti-VCAM-1 (clone: 1.G11B1) monoclonal antibody (1:200), goat anti-mouse-Alexa Fluor 488 secondary antibody (1:200), and phalloidin-Alexa Fluor 594 (1:40; all from Thermo Fisher Scientific). The pHCASMCs were grown in similar conditions and stained using (i) mouse antiICAM-1 (clone: 1A29) monoclonal antibody (1:250) and goat anti-mouse-Alexa Fluor 594 secondary antibody (1:200; both from Thermo Fisher Scientific); (ii) mouse anti-VCAM-1 (clone: 1.G11B1) monoclonal antibody (1:200) and goat anti-mouseAlexa Fluor 488 secondary antibody (1:200; both from Thermo Fisher Scientific); (iii) rabbit anti-CDKN2A/p16INK4a (clone: EPR1473) monoclonal antibody (1:100, Abcam) and donkey anti-rabbit-Alexa Fluor 594 secondary antibody (1:200, Thermo Fisher Scientific); (iv) rabbit anti-NFкB p65 polyclonal antibody (1:200) and donkey anti-rabbit-Alexa Fluor 594 secondary antibody (1:200; both from Thermo Fisher Scientific); and (v) rabbit CCN4/WISP1 polyclonal antibody (1:500) and donkey anti-rabbit-Alexa Fluor 594 secondary antibody (1:200; both from Thermo Fisher Scientific). All incubations with antibodies and/or phalloidin conjugates were carried out, respectively, for $1 \mathrm{~h}$ or $20 \mathrm{~min}$, followed by three washes in PBS. The cells were then counterstained with DAPI (Sigma-Aldrich) for $10 \mathrm{~min}$. All steps were performed at RT. The slides were mounted in Aqua-Poly/Mount (Polysciences) and examined by confocal microscopy. Images were captured by a $\mathrm{C} 1$ laser scanning confocal microscope (Nikon) using a Plan VC Apo $\times 60 / 1.4$ oil objective and Nikon EZ-C1 3.80 software (both from Nikon). The lasers used for DAPI, Alexa Fluor 488, and Alexa Fluor 596 excitations were diode $408 \mathrm{~nm}$ with emission filter 450/35, diode $488 \mathrm{~nm}$ with emission filter 515/30, and He-Ne $543 \mathrm{~nm}$ with emission filter 650LP, respectively. All confocal images of triple-labeled cells were acquired and displayed with identical settings, including laser power, pixel dwell speed, and gain. The gain was set up for optimal visibility of specific proteins. In the case of the lack of possibility to show triple-labeled cells, the gain of the channel for F-actin was downregulated. The fluorescence intensity of selected proteins was quantified using Image (NIH) and EZ-C1 (Nikon).

\section{Immunoblot}

Control pHCAECs and those treated with $100 \mathrm{ng} / \mathrm{ml} \mathrm{TNF} \alpha$ were lysed with RIPA buffer (Sigma-Aldrich) supplemented with Halt protease inhibitor cocktail (Thermo Fisher Scientific). After clarification of lysates $\left(8,000 \times g\right.$ for $10 \mathrm{~min}$ at $\left.4^{\circ} \mathrm{C}\right)$ and normalization of protein concentration by a BCA protein assay kit, $10 \mu \mathrm{g}$ of total protein per lane was separated by SDS-PAGE at $225 \mathrm{~V}$ with Novex WedgeWell 10\%-20\% Tris-glycine gel and Mini Gel Tank (all from Thermo Fisher Scientific). The transfer onto a nitrocellulose membrane was performed by iBlot Dry Western Blotting System (Life Technologies). The membrane was then blocked for $10 \mathrm{~min}$ in a SuperSignal Western Blot Enhancer (Thermo Fisher Scientific) and incubated for $2.5 \mathrm{~h}$ or overnight in an iBind Flex Solution (Thermo Fisher Scientific) with (i) mouse anti-claudin-5 (clone: 4C3C2) monoclonal antibody (1:500) and goat anti-mouse-horseradish peroxidase secondary antibody (HRP, 1:2,000; both from Thermo Fisher Scientific); (ii) mouse anti-GAPDH (clone: ZG003) monoclonal antibody (1:500) and goat anti-mouse-HRP secondary antibody (1:2,000; both from Thermo Fisher Scientific); (iii) mouse anti- $\alpha$-tropomyosin (clone: F-6) monoclonal antibody (1:100, Santa Cruz) and goat anti-mouse-HRP secondary antibody (1:2,000, Thermo Fisher Scientific); (iv) mouse anti-E-selectin (clone: CL2/6) monoclonal antibody (1:100) and goat antimouse-HRP secondary antibody (1:2,000; both from Thermo Fisher Scientific); (v) mouse anti-talin (clone: 8D4) monoclonal antibody (1:100, Sigma-Aldrich) and goat anti-mouse-HRP secondary antibody (1:2,000, Thermo Fisher Scientific); (vi) mouse anti-vinculin (clone: J144) monoclonal antibody $(1: 1,000)$ and goat anti-mouse-HRP secondary antibody (1:2,000; both from Thermo Fisher Scientific); (vii) mouse anti- $\alpha$-catenin (clone: 7A4) monoclonal antibody (1:250) and goat anti-mouseHRP secondary antibody (1:2,000; both from Thermo Fisher Scientific); (viii) mouse anti- $\beta$-catenin (clone: $5 \mathrm{H} 10)$ monoclonal antibody (1:250) and goat anti-mouse-HRP secondary antibody (1:2,000; both from Thermo Fisher Scientific); (iv) rabbit antiVE-cadherin polyclonal antibody (1:500) and goat anti-mouseHRP secondary antibody (1:2,000; both from Thermo Fisher Scientific) using the iBind Flex Western System (Thermo Fisher Scientific). Protein bands were visualized using the 1-Step Ultra TMB-Blotting Solution (Thermo Fisher Scientific). All steps were performed at RT. All western blot assays were performed at least three times. Images were captured by the ChemiDoc MP Imaging System (Bio-Rad). Intensity of bands was quantified using ImageJ (NIH).

\section{Statistical Analysis}

The significant differences between two groups were calculated using an unpaired $t$-test or one-way ANOVA and KruskalWallis test with Dunn's correction for multiple comparisons. Relations between cell migration parameters were assessed using 
Pearson's correlation coefficient analysis. Statistical analyses were performed by using Prism 7 software (GraphPad). The Rayleigh test was used to determine cell movement homogeneity using Chemotaxis and Migration Tool 2.0 (Ibidi). A $p$-value $<0.05$ was considered to be statistically significant and labeled on figures as * or $\$, p<0.05$; $^{* *}$ or $\$ \$, p<0.01$; $^{* * *}$ or $\$ \$, p<0.001$; ${ }^{* * * *}$ or $\$ \$ \$, p<0.0001$; and NS, non-significant. Results were expressed as means $\pm \mathrm{SD}$.

\section{RESULTS}

\section{Tumor Necrosis Factor $\alpha$ Induces Inflammatory Activation of Primary Human Coronary Artery Endothelial Cells}

Given that the use of Escherichia coli as an expression platform for recombinant proteins has several drawbacks (Rosano and Ceccarelli, 2014), we first examined whether rh TNF $\alpha$ expressed in HEK293 cells was able to activate coronary artery endothelial cells. To this end, pHCAECs were cultured to $100 \%$ confluence and then treated for $24 \mathrm{~h}$ with $100 \mathrm{ng} / \mathrm{ml} \mathrm{rh} \mathrm{TNF} \alpha$. We showed $\mathrm{rh}$ $\mathrm{TNF} \alpha$-induced surface and intracellular expressions of functional E-selectin (Figure 1A and Supplementary Figure S1) and VCAM-1 (Supplementary Figures S2A,B). We then examined the interactions between $\mathrm{rh}$ TNF $\alpha$-activated pHCAECs and Jurkat T cells (Figure 1B and Supplementary Video S1). We observed a statistically significant increase in the number of Jurkat $\mathrm{T}$ cells adherent to pHCAECs (from $128.6 \pm 47.00$ per view in the control to $645 \pm 81.01$ in $\mathrm{TNF} \alpha$-activated cells, $p<0.0001$ ) after $30 \mathrm{~min}$ of their co-culture (Figure 1C and Supplementary Figure S2C). Furthermore, we showed a statistically significant increase in the velocity of motile Jurkat $\mathrm{T}$ cells on pHCAECs (from $0.1641 \pm 0.04247$ to $0.4120 \pm 0.07306 \mu \mathrm{m} / \mathrm{min}, p<0.0001$, respectively, for control and $\mathrm{TNF} \alpha$-activated pHCAECs; Figure 1D).

In summary, these data suggest that $\mathrm{rh} \mathrm{TNF} \alpha$ effectively activates pHCAECs and augments flattening, firm adhesion, and further migration of $\mathrm{T}$ cells on the endothelial monolayer.

\section{Tumor Necrosis Factor $\alpha$ Augments the Invasive Potential of Primary Human Coronary Artery Endothelial Cells}

Evidence from in vitro and in vivo data has demonstrated a dual role of $\mathrm{TNF} \alpha$ in the angiogenic response of endothelial cells. It has been shown that $\mathrm{TNF} \alpha$ generally exerts a proangiogenic effect in vivo and antiangiogenic in vitro (Fràter-Schröder et al., 1987; Sainson et al., 2008). However, it seems to function as a stimulatory or inhibitory agent dependent on the model used and experimental condition. As depicted in Supplementary Figures S1, S2B, the exposure of pHCAECs to $100 \mathrm{ng} / \mathrm{ml} \mathrm{rh} \mathrm{TNF} \alpha$ resulted in remarkable changes in the cell morphology, whereby cells appeared enlarged and elongated. We next examined whether these morphological changes were accompanied by enhanced migration capacity of pHCAECs and ability to form tubules on the Matrigel. We first investigated the migration pattern of pHCAECs cultured in the confluence. As shown on rose plots in Figure 2A, during $24 \mathrm{~h}$ of incubation with $100 \mathrm{ng} / \mathrm{ml} \mathrm{rh} \mathrm{TNF} \alpha$, pHCAECs moved in a more persistent manner, with decreased changes in direction, whereas control cells exhibited a more random migration pattern, suggesting that $\mathrm{TNF} \alpha$ promoted directional migration of pHCAECs. This finding was further supported by a high significance of the Rayleigh test (from $p=2.74694 \times 10^{-3}$ to $p=4.90393 \times 10^{-5}$, respectively, for control and TNF $\alpha$-activated cells). As cultured in $100 \%$ confluence for $24 \mathrm{~h}$, there was no effect of rh TNF $\alpha$ on Euclidean distance of migrating cells (Figure 2B). However, the accumulated distance traveled by $\mathrm{rh}$ TNF $\alpha$-activated pHCAECs was significantly shorter compared to the control cells (from 808.8 \pm 146.2 to $573.5 \pm 124.0 \mu \mathrm{m}, p<0.0001$; Figure 2C). Furthermore, we showed a statistically significant decrease in the velocity of these cells (from $0.5656 \pm 0.1023$ to $0.4035 \pm 0.09019 \mu \mathrm{m} / \mathrm{min}$, $p<0.0001$, respectively, for control and TNF $\alpha$-activated cells; Figure 2D). The extended tracking time of migrating cells for up to $36 \mathrm{~h}$ allowed us to demonstrate that longer rh TNF $\alpha$ treatment also promoted the migration of pHCAECs in a more directional manner (Rayleigh test: $p=2.96697 \times 10^{-2}$ vs. $p=4.24461 \times 10^{-5}$; Supplementary Figure S3A) without the effect on Euclidean distance (Supplementary Figure S3B). Longer exposition of $\mathrm{pHCAECs}$ to $\mathrm{rh} \mathrm{TNF} \alpha$ also revealed shorter accumulated distance of migrating cells (1215.0 \pm 194.4 vs. $816.7 \pm 194.6, p<0.0001$; Supplementary Figure S3C) related with their decreased velocity $(0.5626 \pm 0.09002$ vs. $0.3781 \pm 0.09008 \mu \mathrm{m} / \mathrm{min}, p<0.0001$; Supplementary Figure S3D), when compared to untreated pHCAECs. Furthermore, there was a negative correlation between time of treatment and Euclidean distance $(r=-0.5166, p=0.0013)$, accumulated distance $(r=-0.4916, p=0.0023)$, and velocity $(r=-0.4837, p=0.0028$; Supplementary Figures S3EG). Additional analysis revealed that Euclidean distance $(r=0.6206, p<0.0001)$, accumulated distance $(r=0.3723$, $p=0.0253)$, and velocity $(r=0.3790, p=0.0226)$, but not time of treatment, were correlated with the directness of rh $\mathrm{TNF} \alpha$-activated pHCAECs (Supplementary Figure S3I), giving further support for the conclusion that pHCAECs undergo directed migration upon $\mathrm{rh} \mathrm{TNF} \alpha$ treatment. In control cells, we only observed the correlation between directness of cells and Euclidean distance $(r=0.7929, p<0.0001$; Supplementary Figure S3H).

Differently, wound healing (Figure 2E and Supplementary Video S2) and open-field migration (Figure $2 F$ and Supplementary Video S3) assays showed faster migration of rh TNF $\alpha$-activated pHCAECs as compared to the control, especially from the third hour of wound healing experiment or the 12th hour of open migration test.

We further analyzed the protrusion tips during rh $\mathrm{TNF} \alpha$-activated cell migration. As shown in Supplementary Figures S3J,K as well as in Supplementary Videos S2, S3, examination of the leading edge of migrating cells revealed rh $\mathrm{TNF} \alpha$-dependent formation of spindle-shaped leader cells with an aggressive phenotype oriented toward the direction of the movement. Analysis of trajectories of leader cells during the migration of TNF $\alpha$-activated pHCAECs into the open field showed a statistically significant increase in Euclidean distance (from $374.4 \pm 89.41$ to $477.1 \pm 120.4 \mu \mathrm{m}, p=0.0004$, 

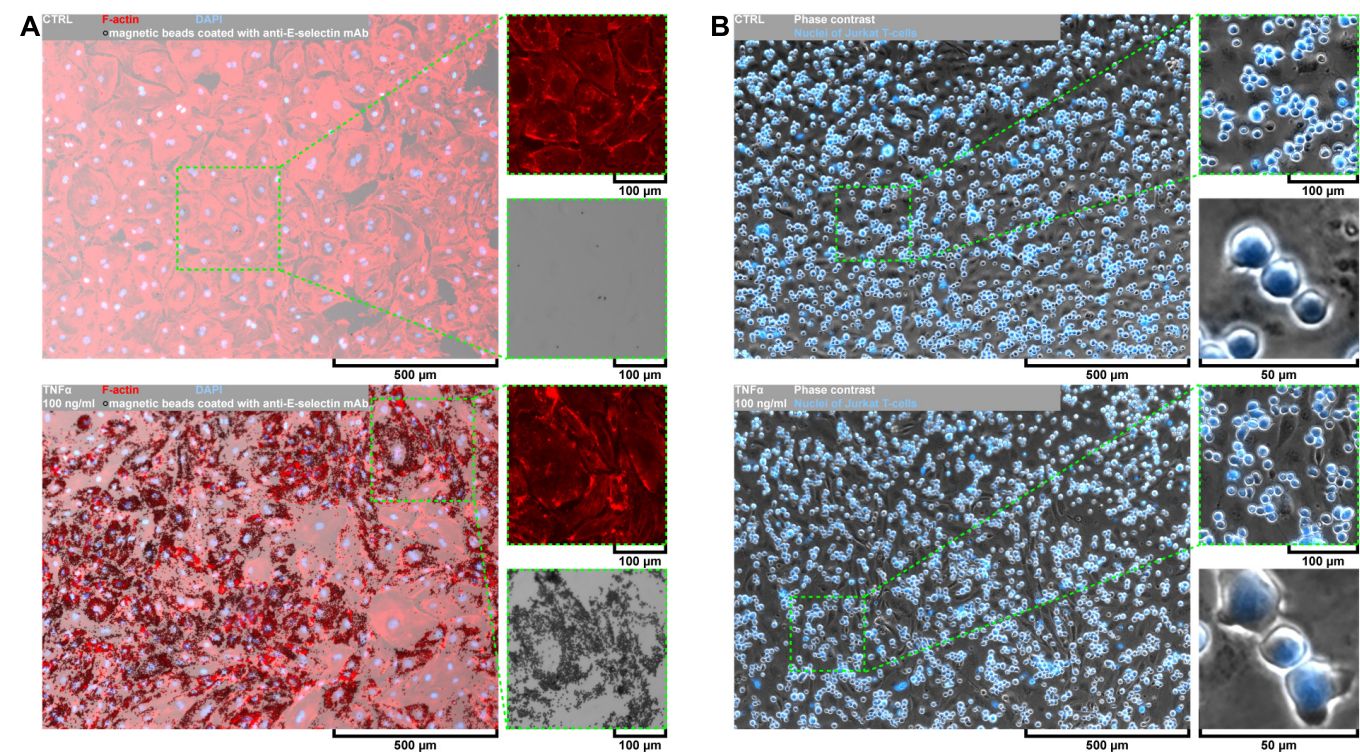
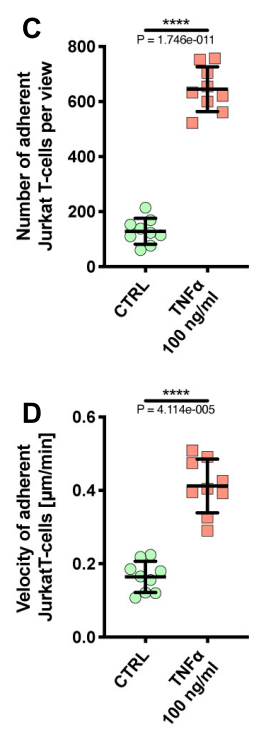

FIGURE 1 | Effect of TNF $\alpha$ on activation of pHCAECs. (A) Representative micrographs of intravital detection of E-selectin using magnetic beads coated with anti-E-selectin monoclonal antibodies (bright field). F-actin (red) and nuclei (blue) were stained fluorescently after fixation. CTRL refers to the control (top panel), TNFa $100 \mathrm{ng} / \mathrm{ml}$ to cells treated with $\mathrm{rh}$ TNF $\alpha$ (bottom panel), mAb to monoclonal antibodies. (B) Representative micrographs of intravital co-culture of pHCAECs (contrast phase) with Jurkat T cells (contrast phase and fluorescence). Nuclei of Jurkat T cells (blue) were stained with Hoechst 33342. CTRL refers to the control (top panel), TNF $\alpha 100 \mathrm{ng} / \mathrm{ml}$ to cells treated with $\mathrm{rh} \mathrm{TNF} \alpha$ (bottom panel). (C) Number of adherent Jurkat T cells to pHCAECs per microscopic field from the control and TNF $\alpha$-activated pHCAECs after 30 min of their co-culture. CTRL refers to the control (top panel), TNF $\alpha 100 \mathrm{ng} / \mathrm{ml}$ to cells treated with rh TNF $\alpha$, ${ }^{* * * *}$ to $p<0.0001$, as determined by unpaired $t$-test. (D) Velocity of motile Jurkat T cells on pHCAECs during 30 min of their co-culture. CTRL refers to the control (top panel), TNF $\alpha$ $100 \mathrm{ng} / \mathrm{ml}$ to cells treated with $\mathrm{rh} \mathrm{TNF} \alpha .{ }^{* \star \star *} p<0.0001$, as determined by unpaired $t$-test.

respectively, for control and TNF $\alpha$-activated cells; Figure 2G), accumulated distances (from $554.1 \pm 94.78$ to $785.1 \pm 138.2 \mu \mathrm{m}$, $p<0.0001$, respectively, for control and TNF $\alpha$-activated cells; Figure $2 \mathrm{H}$ ), and velocity (from $0.3946 \pm 0.07763$ to $0.5703 \pm 0.07103 \mu \mathrm{m} / \mathrm{min}, p<0.0001$, respectively, for control and $\mathrm{TNF} \alpha$-activated cells; Figure 2I), as compared to the control. TNF $\alpha$-induced increase in the migratory potential of pHCAECs was also confirmed by their migration toward the chemo-attractant environment through 3- $\mu \mathrm{m}$ pores (Figure 2J). As shown in Supplementary Figure S3L, we observed a threetimes-higher number of migrating pHCAECs after treatment with $100 \mathrm{ng} / \mathrm{ml} \mathrm{rh} \mathrm{TNF} \alpha$, when compared to the control $(6.667 \pm 3.240$ vs. $22.89 \pm 5.183, p<0.0001)$. We further investigated if rh TNF $\alpha$ had any effect on pHCAEC formation of tube-like structures on Matrigel (Figure 2K and Supplementary Video S4). We observed a statistically significant increase in the number of tubules formed by rh TNF $\alpha$-treated pHCAECs during the experiment (from $97.78 \pm 10.33$ to $141.3 \pm 14.75$ after $3 \mathrm{~h}, p<0.0001$; from $86.56 \pm 5.833$ to $100.2 \pm 5.403$ after $6 \mathrm{~h}$, $p<0.0001$; and from $45.22 \pm 2.386$ to $54.22 \pm 1.856$ after $6 \mathrm{~h}$, $p<0.0001$, respectively, for control and TNF $\alpha$-activated cells; Supplementary Figure S3M).

In summary, these data suggest that in contrast to cooperative migration of control pHCAECs, rh TNF $\alpha$ activates the potential of pHCAECs to collective and coordinated invasion into a new environment through the acquisition of an aggressive phenotype characterized by spindle-like morphology oriented toward the direction of the movement. This ability was remarkably reduced due to contact inhibition between cells when pHCAECs were cultured at a high density in the closed system. The way of migration pattern of control pHCAECs was cooperative.

\section{Tumor Necrosis Factor $\alpha$ Induces Reorganization of the F-Actin Pattern in Primary Human Coronary Artery Endothelial Cells, Leading to the Formation of Aggressive Phenotypes and Reorganization of Cell-Cell Junctions}

Due to remarkable changes in the morphology of $\mathrm{rh}$ TNF $\alpha$-activated pHCAECs and different patterns of their movement, we analyzed the organization of F-actin, distribution of focal adhesion sites, and cell-cell junction proteins. As shown in confocal micrographs in Figures 3A-G, exposition of pHCAECs to $100 \mathrm{ng} / \mathrm{ml} \mathrm{rh} \mathrm{TNF} \alpha$ induced changes in the organizational pattern of F-actin. We observed the transformation of $\mathrm{F}$-actin from the star-like configuration in control pHCAECs into linear stress fibers in rh TNF-activated cells, as well as changes in the organization of focal adhesion sites (Figures 3A,B and Supplementary Video S5). Analyses of the localization of actin-GFP and talin-RFP, as well as fluorescently labeled F-actin and talin, revealed that developed prominent stress fibers in rh TNF $\alpha$-activated pHCAECs were preceded by the formation of tension forces between star-like arranged F-actin bundles within individual cells, which seems to determine the 
A
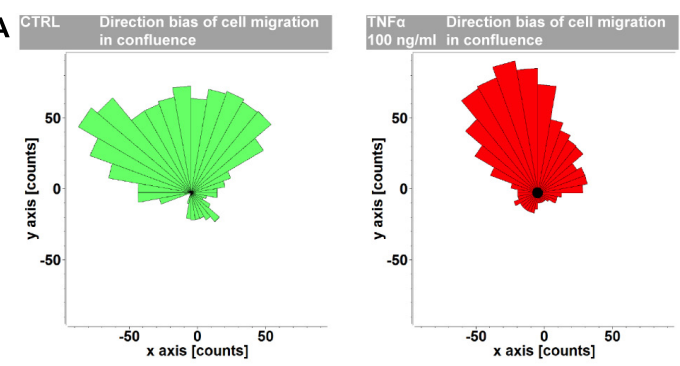

E
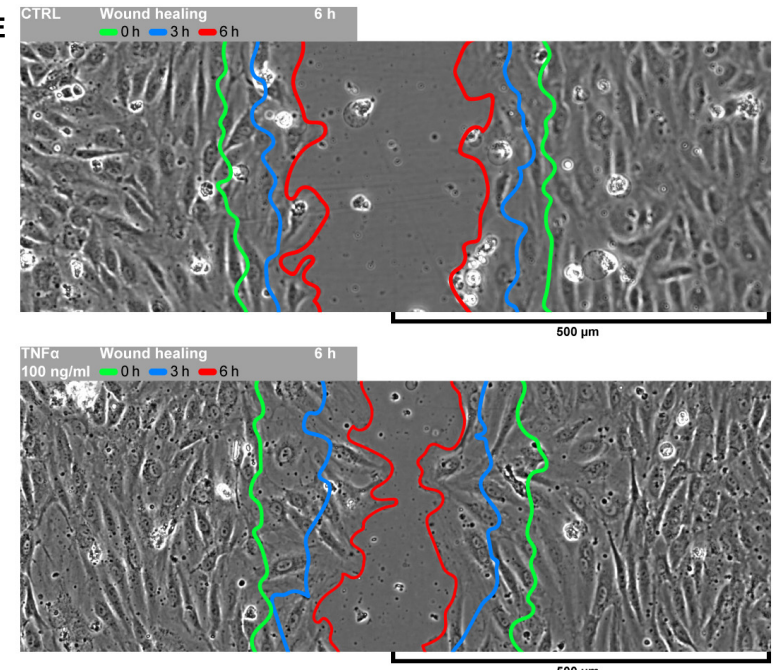
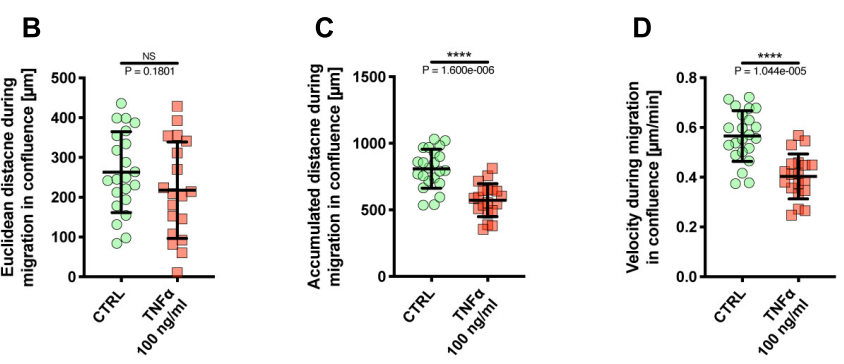

$\mathbf{F}$
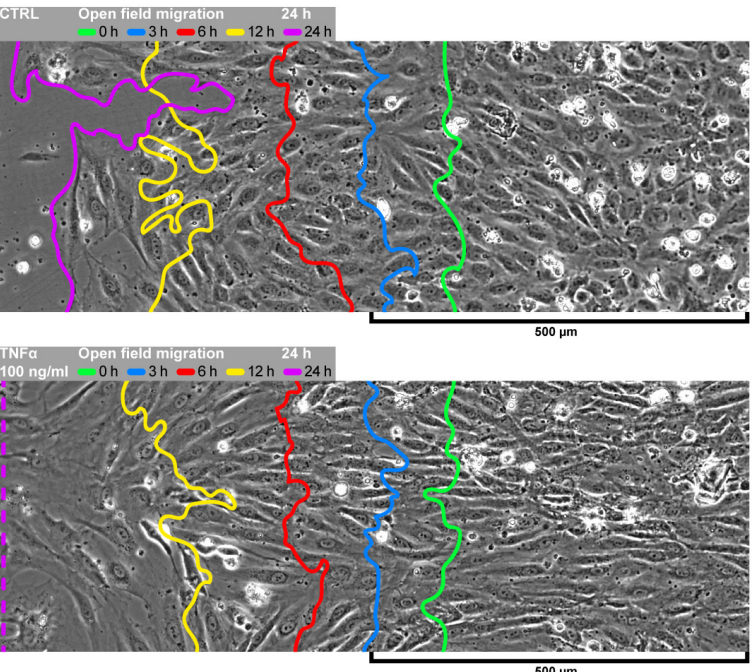

G
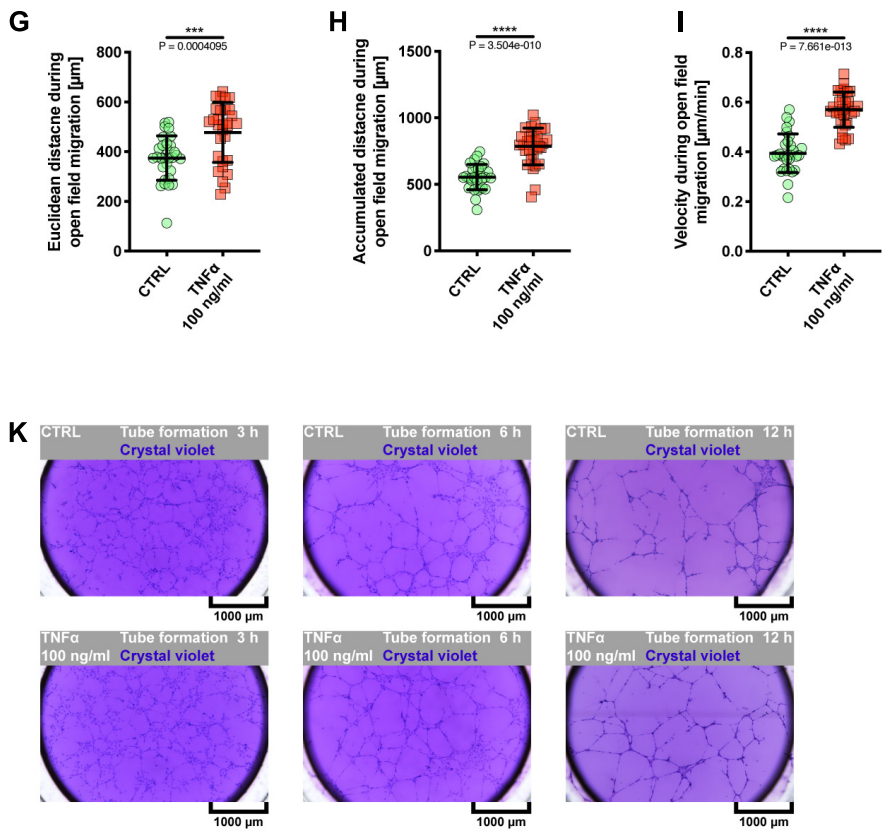
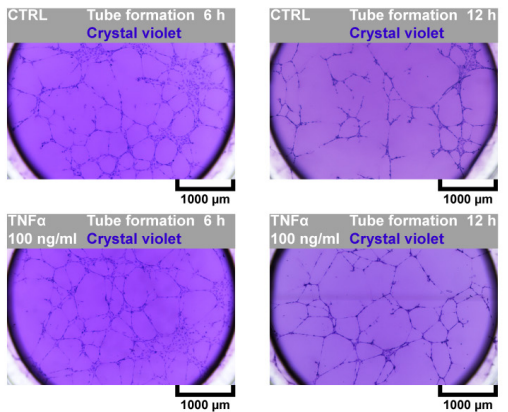

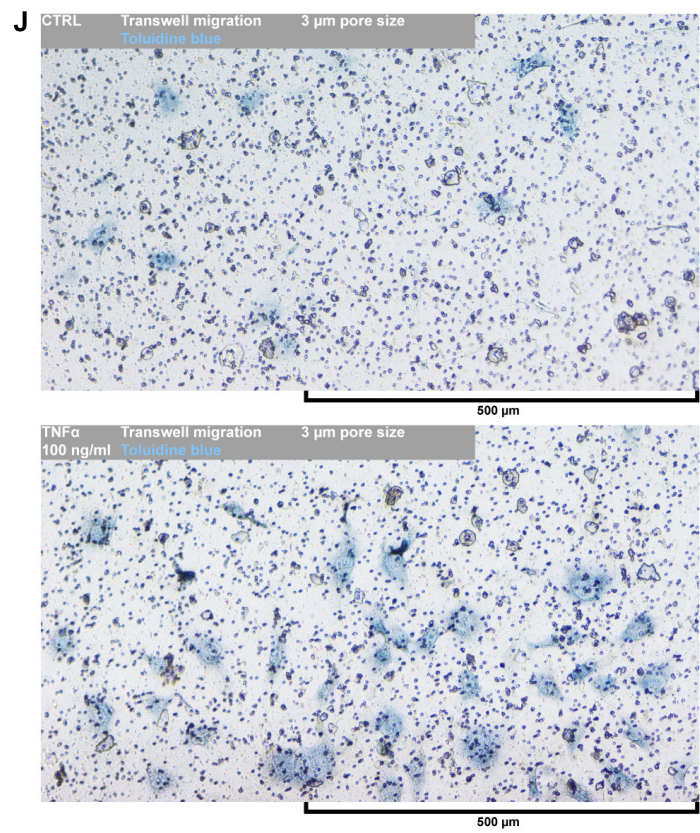

FIGURE 2 | Effect of TNFa on migration of pHCAECs. (A) Rose plot presenting direction bias of pHCAEC migration in confluence within $24 \mathrm{~h}$. CTRL refers to the control (left panel), TNF $\alpha 100 \mathrm{ng} / \mathrm{ml}$ to cells treated with rh TNF $\alpha$ (right panel), ${ }^{* \star}$ to $p<0.01,{ }^{* \star \star \star}$ to $p<0.0001$, as determined by Rayleigh test. (B) Euclidean distance of pHCAECs during 24-h migration in 100\% confluence. CTRL refers to the control, TNF $\alpha 100 \mathrm{ng} / \mathrm{ml}$ to cells treated with rh TNF $\alpha$, NS to non-significant to the control, as determined by unpaired $t$-test. (C) Accumulated distance of pHCAECs during 24 -h migration in $100 \%$ confluence. 


\section{FIGURE 2 | (Continued)}

CTRL refers to the control, TNF $\alpha 100 \mathrm{ng} / \mathrm{ml}$ to cells treated with rh TNF $\alpha$, ${ }^{\star \star \star \star}$ to $p<0.0001$, as determined by unpaired $t$-test. (D) Velocity of pHCAECs during $24-\mathrm{h}$ migration in $100 \%$ confluence. CTRL refers to the control, TNF $\alpha 100 \mathrm{ng} / \mathrm{ml}$ to cells treated with $\mathrm{rh}$ TNF $\alpha,{ }^{\star \star \star \star}$ to $p<0.0001$, as determined by unpaired $t$-test. (E) Representative contrast phase micrographs presenting pHCAEC migration to the wound site. Curves indicate area without cells in $0 \mathrm{~h}$ (green), $3 \mathrm{~h}$ (blue), and $6 \mathrm{~h}$ (red) of the wound healing assay. CTRL refers to the control (upper panel), TNF $\alpha 100 \mathrm{ng} / \mathrm{ml}$ to cells treated with rh TNF $\alpha$ (lower panel). (F) Representative contrast phase micrographs presenting pHCAEC migration to the open field. Curves indicate area without cells in $0 \mathrm{~h}$ (green), $3 \mathrm{~h}$ (blue), $6 \mathrm{~h}$ (red), $12 \mathrm{~h}$ (yellow), and $24 \mathrm{~h}$ (purple) of the open-field migration assay. CTRL refers to the control (upper panel), TNF $\alpha 100 \mathrm{ng} / \mathrm{ml}$ to cells treated with rh TNF $\alpha$ (lower panel). (G) Euclidean distance of pHCAECs during 24-h open-field migration. CTRL refers to the control, TNF $\alpha 100 \mathrm{ng} / \mathrm{ml}$ to cells treated with rh TNF $\alpha$, ${ }^{\star \star \star}$ to $p<0.001$, as determined by unpaired $t$-test. (H) Accumulated distance of pHCAECs during 24-h open-field migration. CTRL refers to the control, TNF $\alpha$ 100 ng/ml to cells treated with rh TNF $\alpha$, ${ }^{\star \star \star \star}$ to $p<0.0001$, as determined by unpaired $t$-test. (I) Velocity of pHCAECs during 24-h open-field migration. CTRL refers to the control, TNF $\alpha 100$ ng/ml to cells treated with rh TNF $\alpha$, ${ }^{\star \star \star \star}$ to $p<0.0001$, as determined by unpaired $t$-test. ( $\left.\mathbf{J}\right)$ Representative bright-field micrographs presenting migration of pHCAECs through 3- $\mu \mathrm{m}$ pores. The cells were stained with toluidine blue. CTRL refers to the control (upper panel), TNF $\alpha 100 \mathrm{ng} / \mathrm{ml}$ to cells treated with rh TNF $\alpha$ (lower panel). (K) Representative bright-field micrographs presenting tube formation by pHCAECs cultured on Matrigel. The tubular structures were stained with crystal violet after $3 \mathrm{~h}$ (left panel), $6 \mathrm{~h}$ (middle panel), and $12 \mathrm{~h}$ (right panel) from seeding. CTRL refers to the control (upper panels), TNF $\alpha 100 \mathrm{ng} / \mathrm{ml}$ to cells treated with rh TNF $\alpha$ (lower panels).

aggressive phenotype of pHCAECs. As shown in Figures 3A,B and Supplementary Video S5, this was related with increased cell-ECM adhesion, whereby adhesion sites were localized along newly formed and parallel-organized F-actin stress fibers (Figures 3A,B). The increased adhesion of rh TNF $\alpha$-activated pHCAECs was confirmed in a wash assay (Supplementary Figures S4A,B). We found a statistically significant increase in the relative number of adherent cells per view after $1 \mathrm{~h}$ (from $1.033 \pm 0.2395$ to $1.153 \pm 0.2252, p=0.0052$, respectively, for control and TNF $\alpha$-activated cells), $2 \mathrm{~h}$ (from $0.9978 \pm 0.2185$ to $1.134 \pm 0.3150, p=0.0378$ ), and $4 \mathrm{~h}$ (from $1.033 \pm 0.2504$ to $1.163 \pm 0.3138, p=0.0225)$ after seeding in complete vascular growth medium supplemented with rh TNF $\alpha$ (Supplementary Figures S4C-F).

Furthermore, we sought to determine whether seeding pHCAECs on different ECM proteins could affect the alignment pattern of stress fibers in response to rh $\mathrm{TNF} \alpha$. Stress fiber organization did not differ depending on ECM protein coatings and was the same as in pHCAECs cultured with rh TNF $\alpha$ on an uncoated surface. Indeed, actin stress fibers were parallel to each other, running along the longer axis of rh $\mathrm{TNF} \alpha$-activated pHCAECs regardless of whether they were cultured on fibronectin (Supplementary Figures S5A,B), laminin (Supplementary Figures S5C,D), collagen I (Supplementary Figures S5E,F), and collagen IV (Supplementary Figures $\mathbf{S 5 G}, \mathbf{H}$ ). It was also noticed that the formation of F-actin stress fibers was associated with increased membrane ruffling (Supplementary Video S5) and formation of punctae cell-cell junctions (Figures 3C-G). Furthermore, the discontinuous cell-cell contact areas in $\mathrm{rh} \mathrm{TNF} \alpha$-activated pHCAECs were characterized by bright fluorescence of AJ proteins, such as VE-cadherin, $\alpha$-catenin, and $\beta$-catenin (Figures 3C-E), and TJ proteins, namely, zonula occludens-1 (ZO-1) and claudin-5 (Figures 3F,G). Although we noticed posttranslational downregulation of claudin-5 after exposition of cells to $\mathrm{rh} \mathrm{TNF} \alpha$, we also showed a strong $95-\mathrm{kDa}$ reactive band, suggesting the oligomerization of claudin-5 (Figure $3 \mathbf{H}$ ) and its different tethering of scaffold protein and F-actin due to different mechanical coupling of adjacent cells and their coordinated movement. Direct participation of AJ and TJ proteins in signalization between rh $\mathrm{TNF} \alpha$-activated cells is presented in the form of surface plots in Figure 3I.
Due to a fundamental role of non-muscle (NM) myosin II, actin-related protein (ARP) $2 / 3$, and rho-associated coiledcoil containing protein kinases 1 and 2 (ROCK-1 and ROCK2 ) in processes that require cellular reshaping and movement (Bhadriraju et al., 2007; Vicente-Manzanares et al., 2009; Smith et al., 2013) and our observations of the effect of $\operatorname{rh} \mathrm{TNF} \alpha$ on F-actin rearrangement, we analyzed the localization of these proteins in both star-like-shaped F-actin bundles and rh $\mathrm{TNF} \alpha$-induced cortical F-actin stress fibers or sites of punctae cell-cell junctions. As shown in the left panel of Figures 4AE, NM myosin IIb, ARP 2/3 1B, and ROCK-1 were localized in star-like-shaped F-actin structures, indicating their role in the cooperative transmission of tensions between adjacent cells. Interestingly, $\mathrm{TNF} \alpha$-activated cells expressed NM myosin IIa, ARP 2/3 1B, and ROCK-1 in the regions of punctae cell-cell junctions (right panel in Figures $4 \mathbf{A}-\mathbf{E}$ ). These observations were confirmed by the analysis of the colocalization with F-actin (Figure 4F) and determined the tensional character of discontinuous junctions between rh TNF $\alpha$-activated pHCAECs.

In summary, these data, at least partially, explain the change in the migration pattern of pHCAECs in response to rh TNF $\alpha$ (from cooperative in the control into coordinated in rh TNF $\alpha$-activated cells). We suggest that the star-like-shaped organization of F-actin bundles determines the propensity of pHCAECs to cooperative migration, important in effective contribution of 'seal the gaps' function, whereas rh TNF $\alpha$-induced formation of prominent, parallel stress fibers and subsequent organization of punctae, but strong cell-cell junctions, allows for the directed and parallel motion of the cells during coordinated migration.

\section{Tumor Necrosis Factor $\alpha$ Induces Formation of Migrasomes Involved in Cell-Cell Signalization Between Migrating Primary Human Coronary Artery Endothelial Cells}

Directional cell migration requires the series of changes in the structure and function of the cell at its different regions. These cover the formation of membrane-bounded cellular extensions at the leading edge and consequent retraction of the rear edge of the cell. It is widely accepted that tail retraction precedes and induces changes in migration direction and serves to maintain 


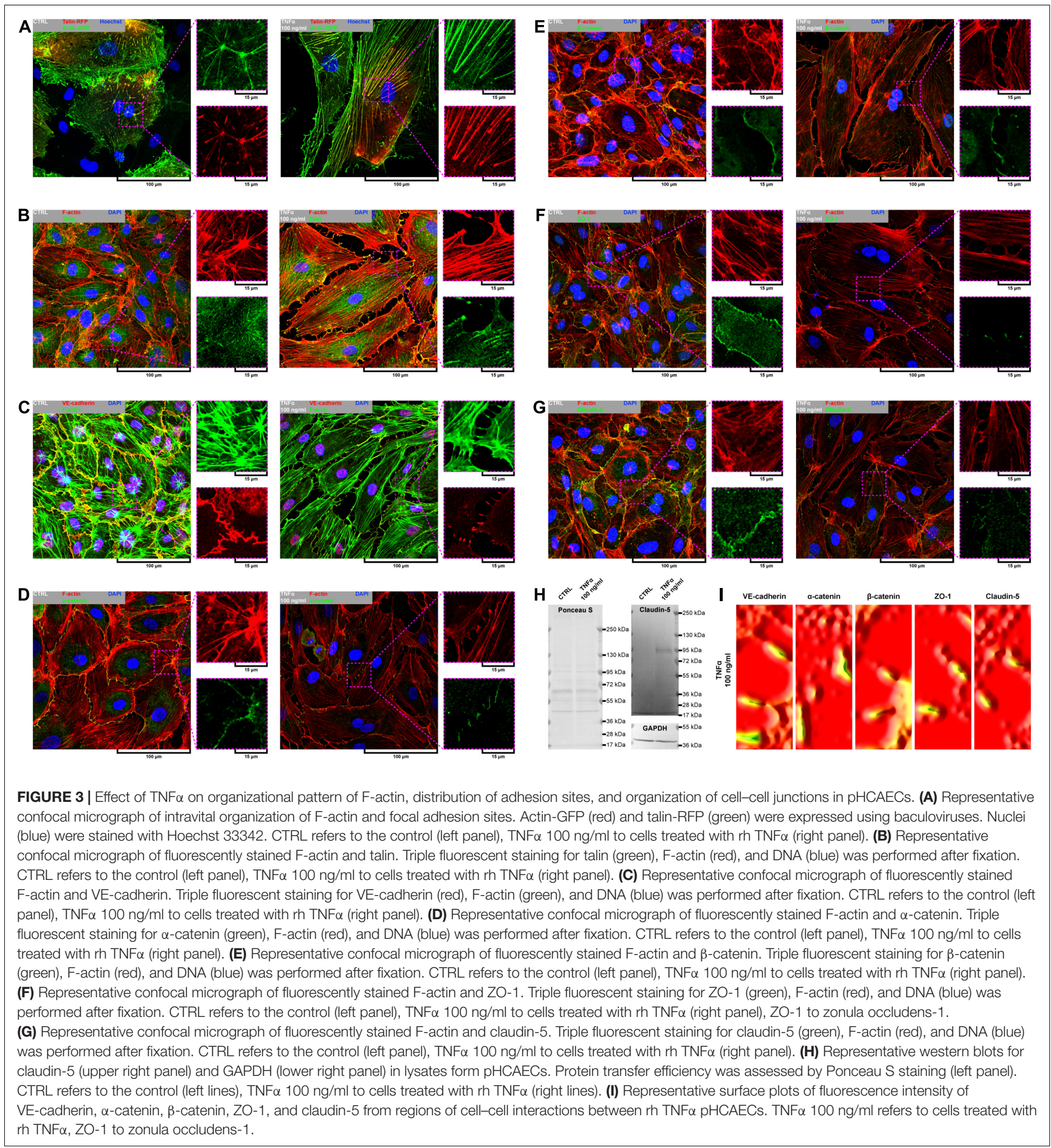

directionality of the force-generating leading edge of the cell (Xue et al., 2010; Theisen et al., 2012). During rh TNF $\alpha$-induced coordinated migration of pHCAECs, we observed intensified formation of retraction fibers behind cells (Figures 5A-D). As shown Figures 5A-E and Supplementary Video S5, these long and tubular structures were rich in F-actin, and their formation resulted in increased adhesion and interactions between cells at the rear of migrating cells. We demonstrated that the tips of retraction fibers were continuously or discontinuously connected to the neighboring cells and were characterized by augmented adhesion, suggesting their role in transmission of F-actin-based mechanical forces for proper polarization of adjacent cells and coordination of their migration. These forces were generated by rapid contraction of retraction fibers toward the direction 


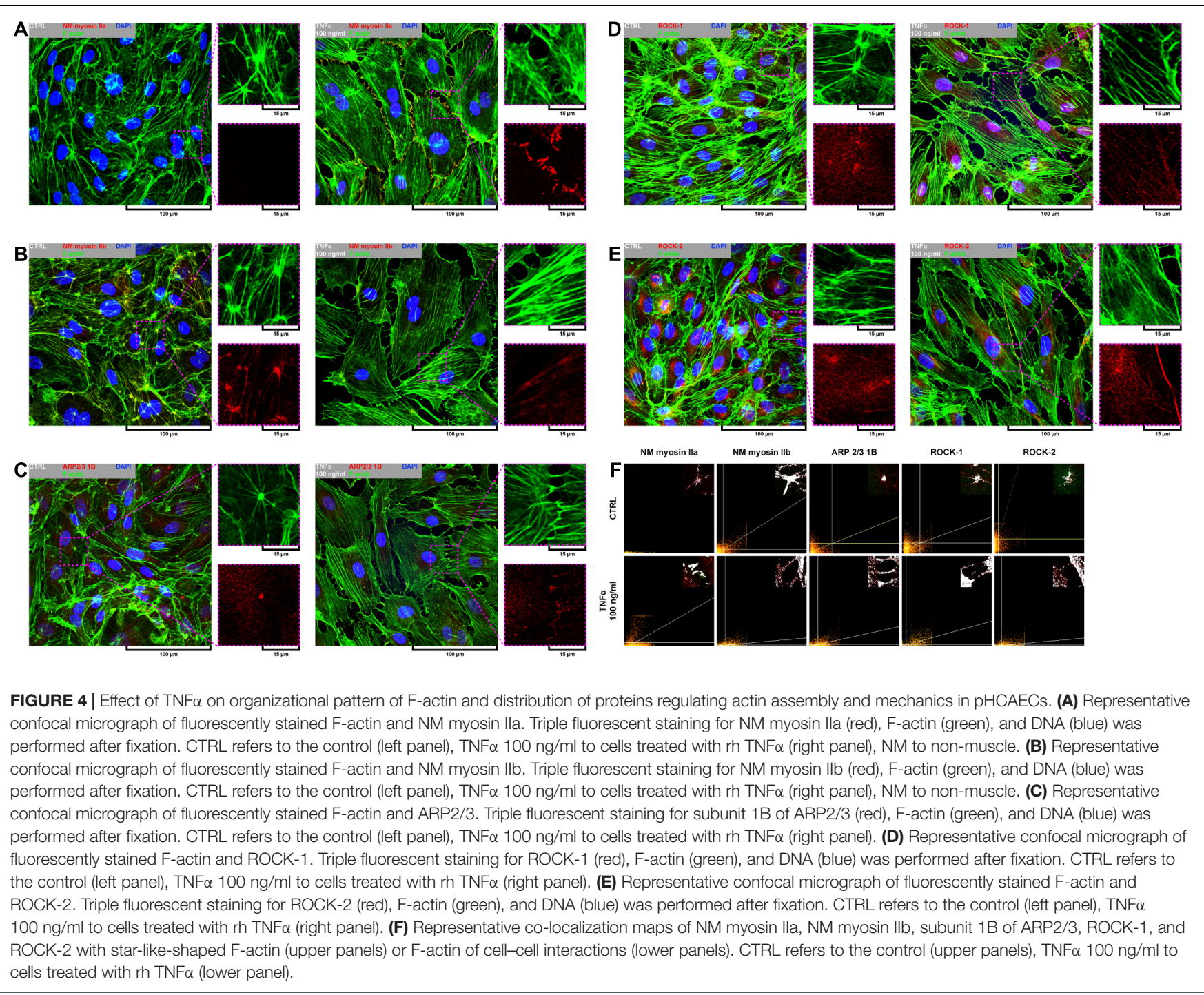

of cell movement (Figure 5F and Supplementary Video S5). We also frequently observed formation of migrasomes at tips or the course of retraction fibers and their release by breaking the retraction fibers (Supplementary Video S5). Moreover, as shown in Figures 5G-J, the released migrasomes tended to occur at points of cell-cell and cell-ECM contact. We also noticed that during retraction fiber breakage, some migrasomes may be released to the cell culture medium, where they seem to play a role in intercellular signalization promoting directed cell migration (Supplementary Video S6).

In summary, these data show possible ways of signalization between $\mathrm{TNF} \alpha$-activated pHCAECs during their migration. The first concerns the generation of mechanical forces during contraction of retraction fibers, and the other one is related to migracytosis. We suggest here that the formation and release of migrasomes are highly related to increased adhesion and strength of punctae or continuous intercellular junctions at the tips of retraction fibers. Moreover, our observations allow us to assume that migrasomes released by
TNF $\alpha$-activated pHCAECs are involved in signalization between migrating pHCAECs.

\section{Activation of Endogenous Expression of TPM1 Inhibits Tumor Necrosis Factor $\alpha$-Induced Inflammatory Response of Primary Human Coronary Artery Endothelial Cells and Force-Dependent Opening of Their Cell-Cell Junctions}

It was shown by Tremblay et al. (2006) and in Figure 1 or Supplementary Figure S1 that E-selectin is the trigger of transendothelial migration but also accumulates quickly at punctae cell-cell junctions of activated endothelial cells, where it co-localizes with F-actin (Tremblay et al., 2006). We have previously shown that stabilization of F-actin by overexpression of $\alpha$-tropomyosin protects endothelial integrity against Lhomocysteine and cigarette smoke extract in EA.hy926 (Gagat et al., 2013, 2014). Similarly, our further studies revealed that 

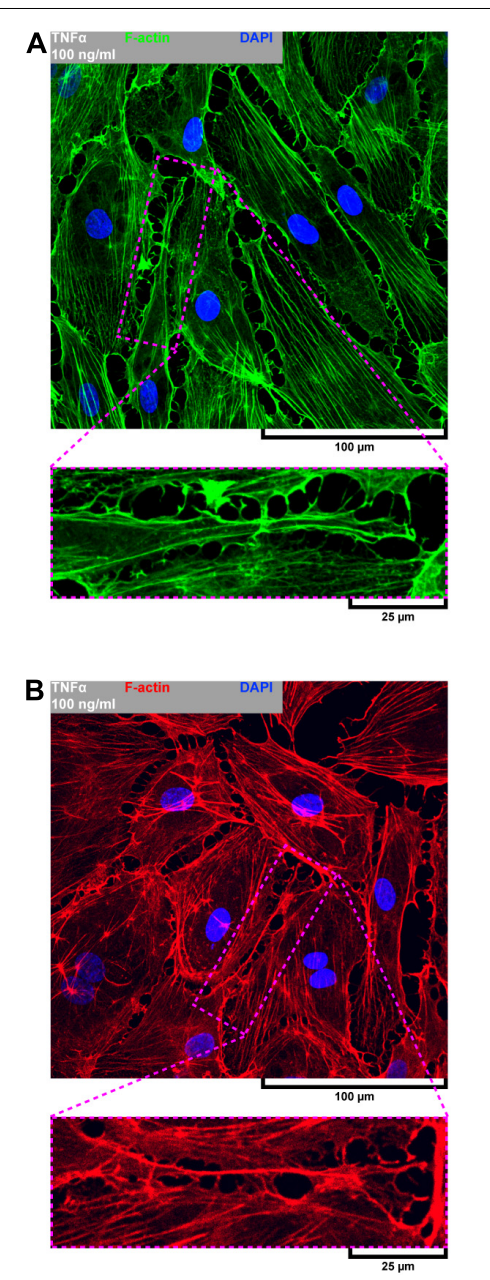
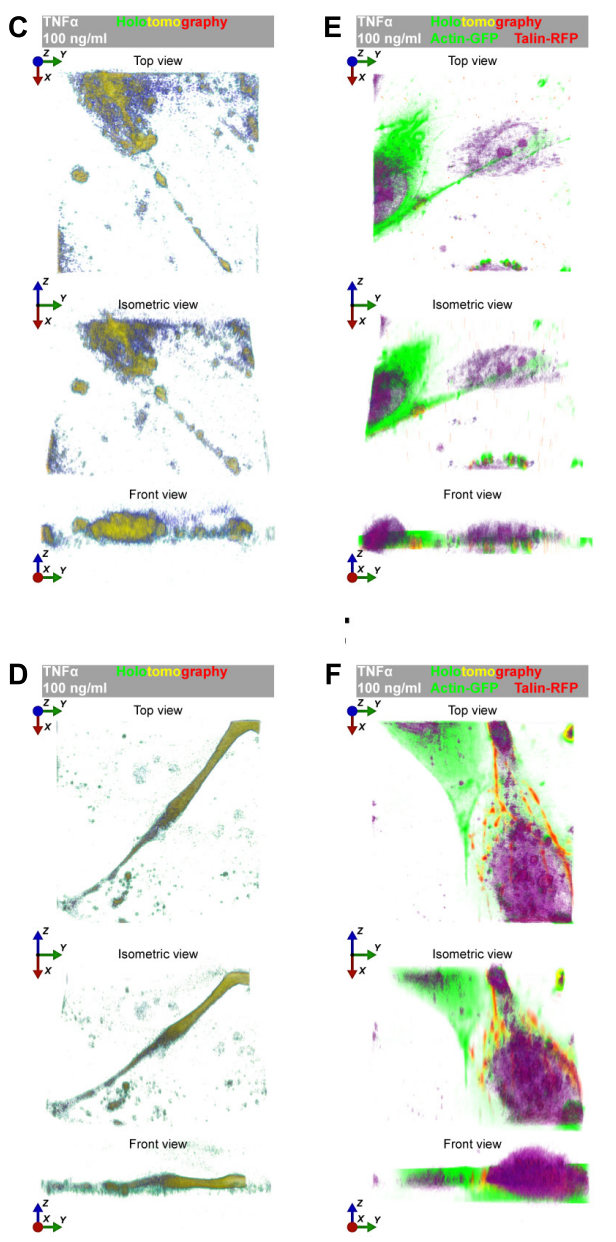
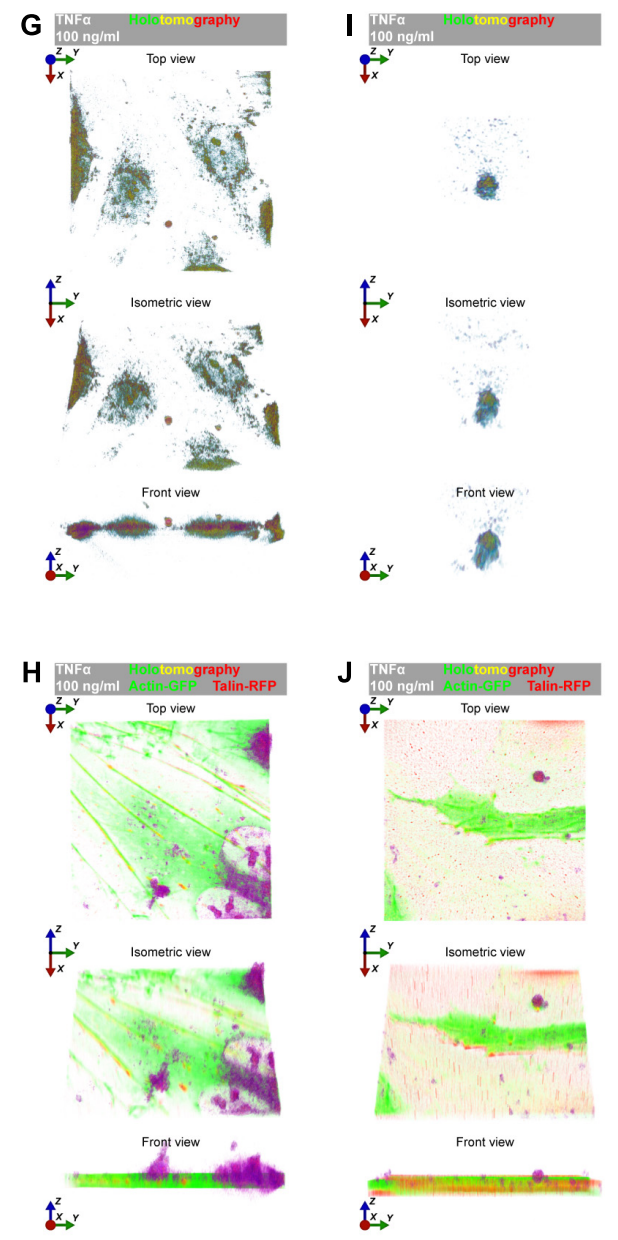

FIGURE 5 | TNF $\alpha$-induced formation of migrasomes and migracytosis. (A) Representative confocal micrograph of fluorescently stained F-actin. Double fluorescent staining for F-actin (green) and DNA (blue) was performed after fixation. TNF $\alpha 100 \mathrm{ng} / \mathrm{ml}$ to cells treated with rh TNF $\alpha$. (B) Representative confocal micrograph of fluorescently stained F-actin. Double fluorescent staining for F-actin (red) and DNA (blue) was performed after fixation. TNF $\alpha 100$ ng/ml to cells treated with rh TNF $\alpha$. (C,D,G,I) Representative intravital holotomography micrographs of pHCAECs forming and releasing migrasomes. TNF $\alpha 100 \mathrm{ng} / \mathrm{ml}$ to cells treated with rh TNF $\alpha$. $\mathbf{( E , F , H , J ) ~ R e p r e s e n t a t i v e ~ i n t r a v i t a l ~ c o r r e l a t i v e ~ h o l o t o m o g r a p h i c ~ a n d ~ f l u o r e s c e n c e ~ m i c r o g r a p h s ~ o f ~ p H C A E C s ~ f o r m i n g ~ a n d ~ r e l e a s i n g ~ m i g r a s o m e s . ~ A c t i n - G F P ~ ( r e d ) ~ a n d ~}$ talin-RFP (green) were expressed using baculoviruses. TNF $\alpha 100 \mathrm{ng} / \mathrm{ml}$ to cells treated with rh TNF $\alpha$.

overexpression of $\alpha$-tropomyosin preserves transformed alveolar epithelial cell-cell junctions against disintegration induced by cigarette smoke extract (Gagat et al., 2016). Here, we investigated the effect of CRISPR-based regulation of endogenous TPM1 expression on the activation and posttranslational expression of cell-cell and cell-ECM adhesion proteins. First, we activated or deactivated endogenous expression of TPM1 using CRISPR TPM1 activation or knockout systems introduced to the cells by the nucleofection technique (Figures 6A,B). As shown in Figure 6C, the CRISPR systems worked effectively on modulating $\alpha$-tropomyosin expression in pHCAECs (from $0.888 \pm 0.0578$ to $1.093 \pm 0.0781, p=0.0044$ and to $0.305 \pm 0.0122$, $p<0.0001$, respectively, for CRISPR TPM1 activation and knockout systems). Furthermore, we showed that activation of endogenous expression of TPM1 itself downregulated posttranslational expression of E-selectin (from $0.308 \pm 0.0515$, $p=0.0112$, and $0.584 \pm 0.0753, p=0.0002$, to $0.138 \pm 0.0409$, respectively, as compared to the cells transfected with CRISPR control and knockout systems and inhibited rh TNF $\alpha$-induced activation of pHCAECs (Figure 6D). Next, we investigated the effect of endogenous expression of TPM1 on posttranslational expression of talin. Due to its essential role in mediating cell adhesion, most of the studies regarding talin have focused mainly on talin-1. However, talin-2 is required for the generation of traction force and formation of invadopodia (Qi et al., 2016). We observed that activation of endogenous TPM1 expression itself downregulated posttranslational expression of talin-2 (from $0.840 \pm 0.0421$ to $0.274 \pm 0.0066, p<0.0001$ ), whereas TPM1 knockdown led to a downregulation of both talin-1 (from $1.169 \pm 0.0417$ to $0.146 \pm 0.0082, p<0.0001)$ and talin$2(0.840 \pm 0.0421$ to $0.516 \pm 0.0293, p<0.0001)$. After $\mathrm{rh}$ $\mathrm{TNF} \alpha$ treatment, we also noticed decreased expression of talin2 (from $0.274 \pm 0.0066$ to $0.188 \pm 0.0239, p=0.0037$ ) in TPM1 upregulated cells and its increase in TPM1-knockdown 

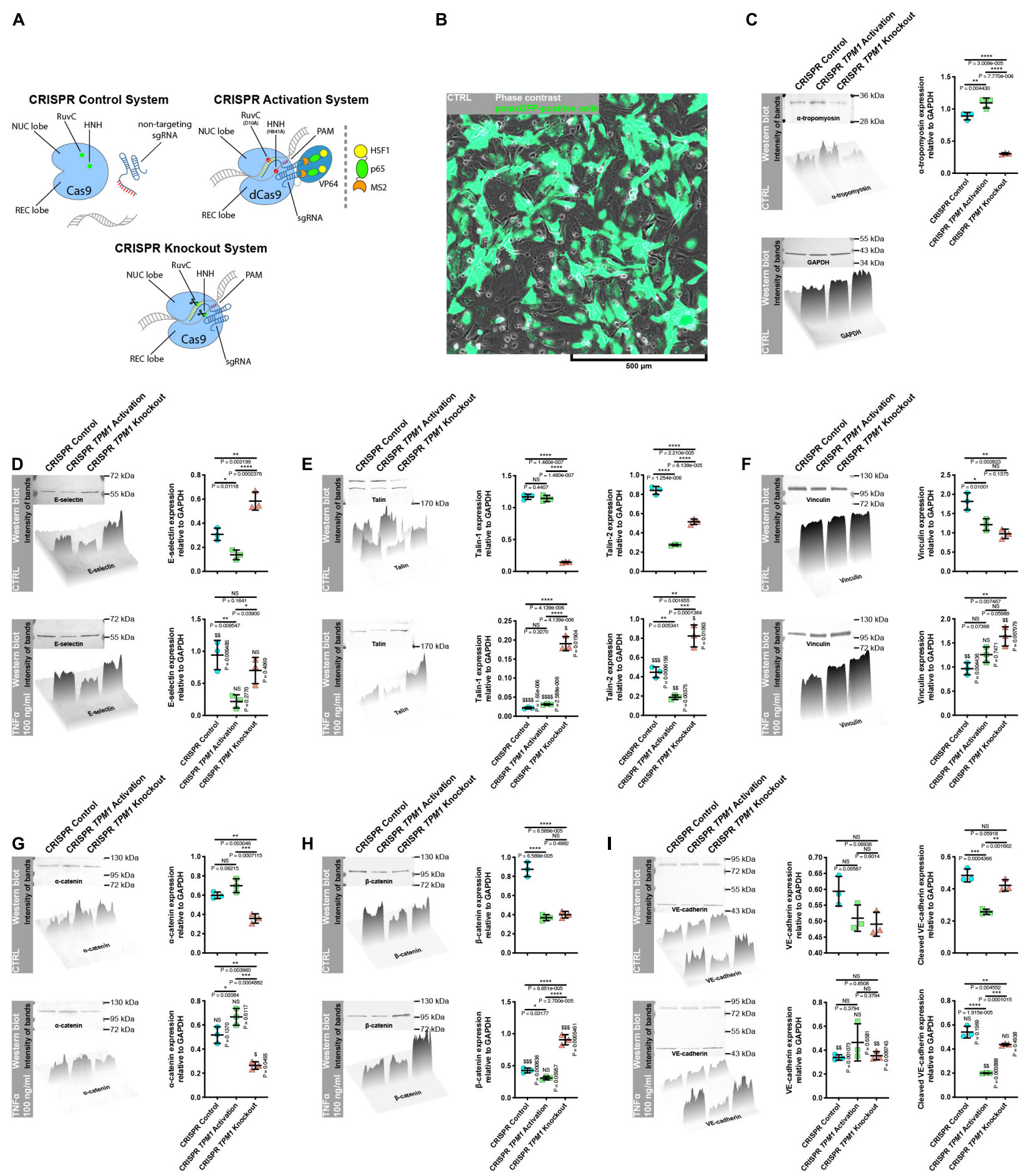

FIGURE 6 | Effect of TNF $\alpha$ on posttranslational expression of cell-cell and cell-ECM junctional proteins in pHCAECs with CRISPR-based modulated expression of TPM1. (A) Schematic overview of CRISPR systems used in regulation of TPM1 expression in pHCAECs. The cells were nucleofected with a CRISPR control plasmid encoding the Cas9 nuclease and a non-specific guide RNA (upper left panel), CRISPR TPM1 activation system encoding the nuclease-deficient dCas9 fused to the transactivation domain VP64, a plasmid encoding the MS2-p65-HSF1 fusion protein, and a guide RNA targeting sequences upstream of the TPM1 transcriptional start site (upper left panel) or CRISPR TPM1-knockout system encoding the Cas9 nuclease and a TPM1-specific 20-nt guide RNA (lower panel). (B) Representative micrograph of intravital detection of pmaxGFP plasmid product (green fluorescence) in nucleofected pHCAECs (contrast phase). (C) Representative western blots, surface plot, and densitometric analysis for $\alpha$-tropomyosin (upper panel) and GAPDH (lower panel). CTRL refers to the control, ${ }^{* \star}$ to $p<0.01,{ }^{* \star \star \star}$ to $p<0.0001$. (D) Representative western blots, surface plot, and densitometric analysis for E-selectin. CTRL refers to the control (upper panel), TNF $\alpha 100 \mathrm{ng} / \mathrm{ml}$ to cells treated with rh TNF $\alpha$ (lower panel), NS to non-significant, ${ }^{*}$ to $p<0.05,{ }^{\star \star}$ to $p<0.01,{ }^{\star \star \star \star} p<0.0001$, as determined by the Kruskal-Wallis test, $\$ \$$ to $p<0.01$, as

(Continued) 
FIGURE 6 | (Continued)

determined by unpaired $t$-test. (E) Representative western blots, surface plot, and densitometric analysis for talin. CTRL refers to the control (upper panel), TNF $\alpha$ $100 \mathrm{ng} / \mathrm{ml}$ to cells treated with rh TNF $\alpha$ (lower panel), NS to non-significant, ${ }^{* \star}$ to $p<0.01,{ }^{\star \star *}$ to $p<0.001,{ }^{* \star \star \star}$ to $p<0.0001$, as determined by the Kruskal-Wallis test, $\$ \$$ to $p<0.01, \$ \$$ to $p<0.001, \$ \$ \$ p<0.0001$, as determined by unpaired $t$-test. (F) Representative western blots, surface plot, and densitometric analysis for vinculin. CTRL refers to the control (upper panel), TNF $\alpha 100 \mathrm{ng} / \mathrm{ml}$ to cells treated with rh TNF $\alpha$ (lower panel), NS to non-significant, ${ }^{*}$ to $p<0.05$, ${ }^{\star *}$ to $p<0.01$, as determined by the Kruskal-Wallis test, $\$ \$$ to $p<0.01$, as determined by unpaired $t$-test. (G) Representative western blots, surface plot, and densitometric analysis for $\alpha$-catenin. CTRL refers to the control (upper panel), TNF $\alpha 100 \mathrm{ng} / \mathrm{ml}$ to cells treated with rh TNF $\alpha$ (lower panel), NS to non-significant, ${ }^{*}$ to $p<0.05$, ${ }^{\star *}$ to $p<0.01$, ${ }^{\star \star \star}$ to $p<0.001$, as determined by the Kruskal-Wallis test, $\$$ to $p<0.05$, as determined by unpaired $t$-test. (H) Representative western blots, surface plot, and densitometric analysis for $\beta$-catenin. CTRL refers to the control (upper panel), TNF $\alpha 100 \mathrm{ng} / \mathrm{ml}$ to cells treated with rh TNF $\alpha$ (lower panel), NS to non-significant, * to $p<0.05$, ${ }^{\star \star \star \star}$ to $p<0.0001$, as determined by the Kruskal-Wallis test, $\$ \$ \$$ to $p<0.001$, as determined by unpaired $t$-test. (I) Representative western blots, surface plot, and densitometric analysis for VE-cadherin. CTRL refers to the control (upper panel), TNF $\alpha 100$ ng/ml to cells treated with rh TNF $\alpha$ (lower panel), NS to non-significant, ${ }^{\star \star}$ to $p<0.01,{ }^{\star \star *}$ to $p<0.001,{ }^{\star \star \star \star}$ to $p<0.0001$, as determined by the Kruskal-Wallis test, $\$ \$$ to $p<0.01$, as determined by unpaired $t$-test.

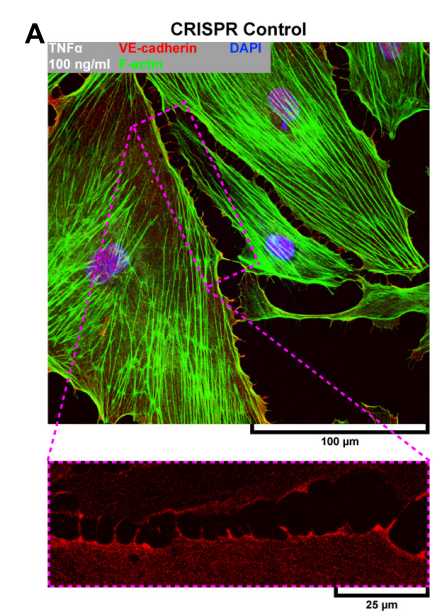

C

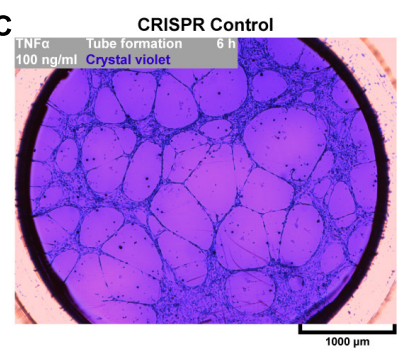

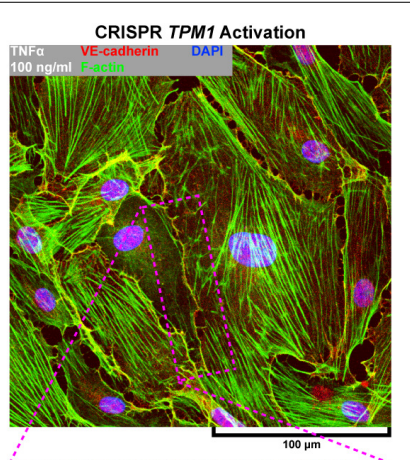

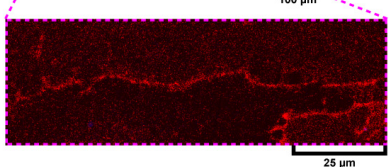

CRISPR TPM1 Activation

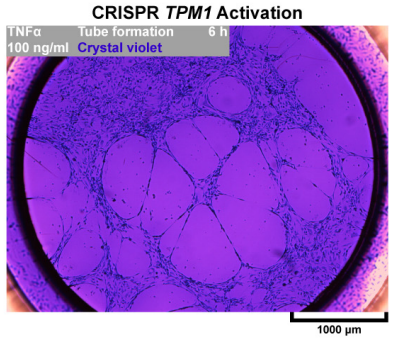

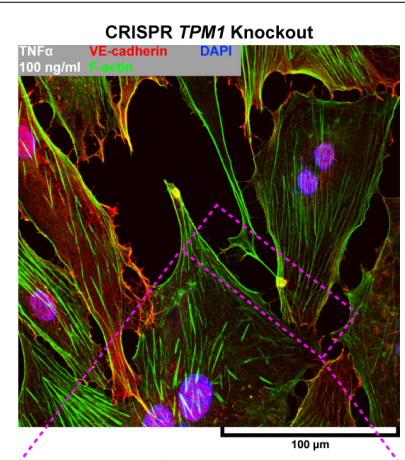
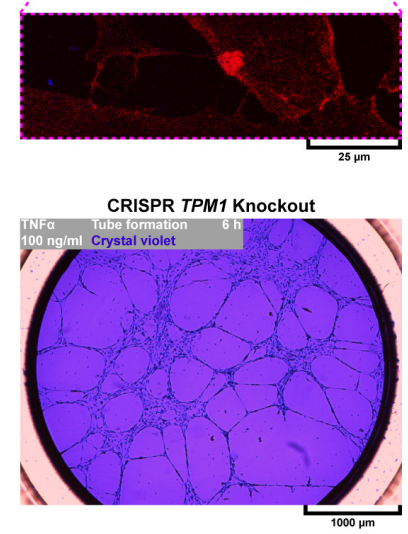

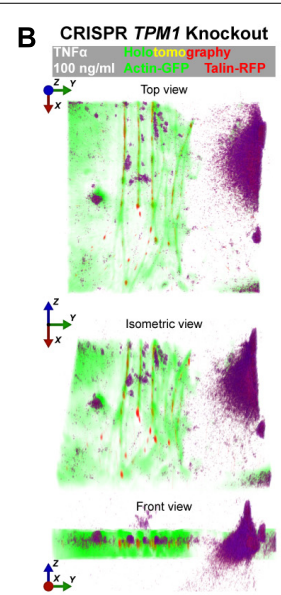

D

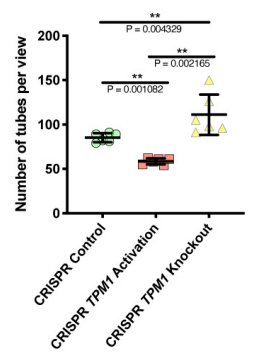

FIGURE 7 | Effect of CRISPR-based regulated expression of TPM1 on F-actin organization, continuity of cell-cell junctions, and proangiogenic prosperities of TNF $\alpha$-activated pHCAECs. (A) Representative confocal micrographs of fluorescently stained F-actin and VE-cadherin. Triple fluorescent staining for VE-cadherin (red), F-actin (green), and DNA (blue) was performed after fixation of pHCAECs nucleofected with CRISPR control (left panel), CRISPR TPM1 activation (middle panel), or CRISPR TPM1-knockout systems (right panel). TNF $\alpha 100 \mathrm{ng} / \mathrm{ml}$ refers to cells treated with rh TNF $\alpha$ (right panel). (B) Representative intravital correlative holotomographic and fluorescence micrographs of pHCAECs nucleofected with the CRISPR TPM1-knockout system. Actin-GFP (red) and talin-RFP (green) were expressed using baculoviruses. TNF $\alpha 100 \mathrm{ng} / \mathrm{ml}$ to cells treated with rh TNF $\alpha$. (C) Representative bright-field micrographs presenting tube formation by pHCAECs nucleofected with CRISPR control (left panel), CRISPR TPM1 activation (middle panel), and CRISPR TPM1-knockout systems cultured on Matrigel. The tubular structures were stained with crystal violet after $6 \mathrm{~h}$ from seeding. TNF $\alpha 100 \mathrm{ng} / \mathrm{ml}$ refers to cells treated with rh TNF $\alpha$. (D) Number of tubes per microscopic field formed by TNF $\alpha$-activated pHCAECs with CRISPR-based regulated expression of TPM1. ** refers to $p<0.01$, as determined by the Kruskal-Wallis test.

pHCAECs (from $0.516 \pm 0.0293$ to $0.824 \pm 0.1143, p=0.0106$. We did not observe expression of talin-1 in rh TNF $\alpha$-activated pHCAECs transfected with CRISPR control and TPM1 activation systems (Figure 6E). Talin-2 has been shown to be able to recruit vinculin in the absence of mechanical force (Austen et al., 2015). It has also been suggested that vinculin coordinates polarized cell motility and plays a central role in the regulation of endothelial barrier function via dynamic balance between centripetal forces generated by contraction of stress fibers attached to focal adhesion sites and tethering forces applied by intracellular complexes (Birukova et al., 2016). Interestingly, here, we showed similar, and independent of $\mathrm{rh} \mathrm{TNF} \alpha$ treatment, posttranslational levels of vinculin in pHCAECs with activated TPM1 expression. Differently, we noticed rh $\mathrm{TNF} \alpha$-induced upregulation of vinculin in cells transfected with the CRISPR TPM1-knockout system (from $0.973 \pm 0.1228$ to $1.637 \pm 0.1992, p=0.0080$; Figure 6F). Both $\alpha$-catenin and vinculin cooperatively support the strength of intercellular adhesion via a mechanoresponsive 

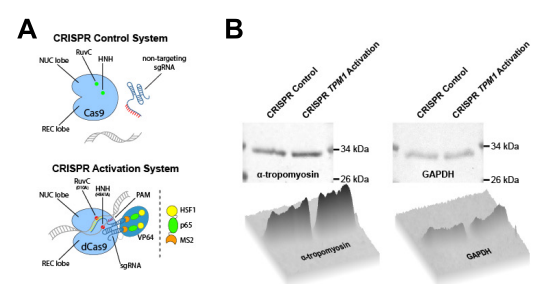

E
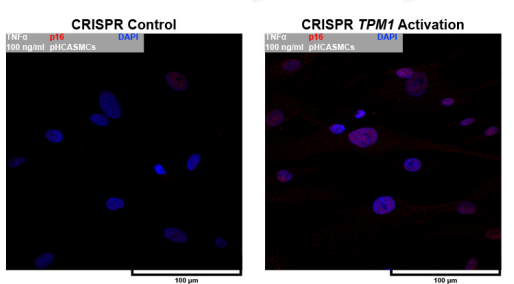

H
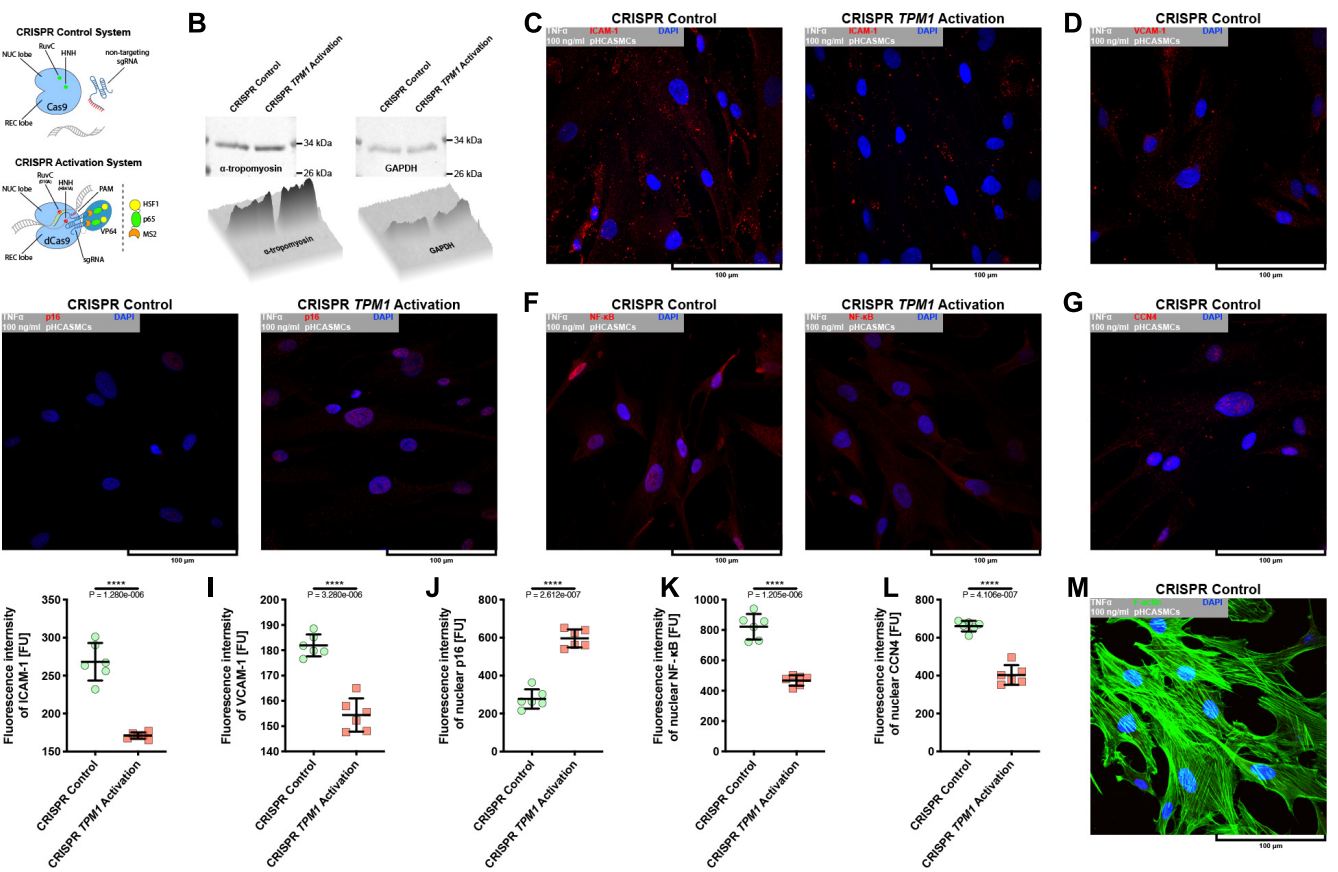

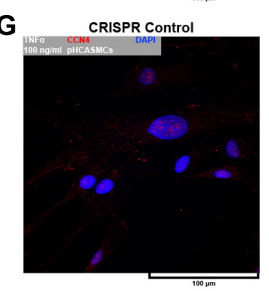

M

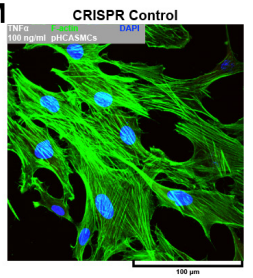

CRISPR TPM1 Activatio

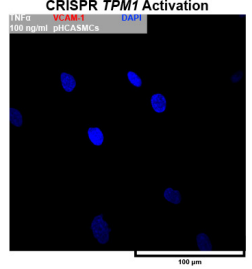

CRISPR TPM1 Activation

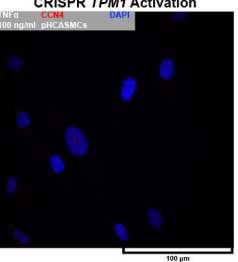

CRISPR TPM1 Activation

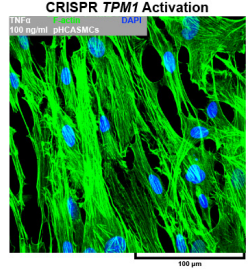

FIGURE 8 | Effect of CRISPR-based activation of endogenous TPM1 expression on expression of molecular markers of TNF $\alpha$-stimulated pHCASMC migration and proliferation. (A) Schematic overview of CRISPR systems used in regulation of TPM1 expression in pHCASMCs. The cells were nucleofected with CRISPR control plasmid encoding the Cas9 nuclease and a non-specific guide RNA (upper panel) or CRISPR TPM1 activation system encoding the nuclease-deficient dCas9 fused to the transactivation domain VP64, a plasmid encoding the MS2-p65-HSF1 fusion protein, and a guide RNA targeting sequences upstream of TPM1 transcriptional start site (lower panel). (B) Representative western blots and surface plots for $\alpha$-tropomyosin (left panel) and GAPDH (right panel) in lysates form pHCAECs.

(C) Representative confocal micrographs of fluorescently stained ICAM-1. Double fluorescent staining for ICAM-1 (red) and DNA (blue) was performed after fixation of TNF $\alpha$-stimulated pHCASMCs nucleofected with CRISPR control (left panel) or CRISPR TPM1 activation systems (right panel). TNF $\alpha 100$ ng/ml to cells treated with rh TNF $\alpha$. (D) Representative confocal micrographs of fluorescently stained VCAM-1. Double fluorescent staining for VCAM-1 (red) and DNA (blue) was performed after fixation of TNF $\alpha$-stimulated pHCASMCs nucleofected with CRISPR control (left panel) or CRISPR TPM1 activation systems (right panel). TNF $\alpha$ $100 \mathrm{ng} / \mathrm{ml}$ refers to cells treated with rh TNF $\alpha$. (E) Representative confocal micrographs of fluorescently stained p16. Double fluorescent staining for p16 (red) and DNA (blue) was performed after fixation of TNF $\alpha$-stimulated pHCASMCs nucleofected with CRISPR control (left panel) or CRISPR TPM1 activation systems (right panel). TNF $\alpha 100 \mathrm{ng} / \mathrm{ml}$ refers to cells treated with rh TNF $\alpha$. (F) Representative confocal micrographs of fluorescently stained NFKB. Double fluorescent staining for NFKB (red) and DNA (blue) was performed after fixation of TNF $\alpha$-stimulated pHCASMCs nucleofected with CRISPR control (left panel) or CRISPR TPM1 activation systems (right panel). TNF $\alpha 100 \mathrm{ng} / \mathrm{ml}$ refers to cells treated with rh TNF $\alpha$. (G) Representative confocal micrographs of fluorescently stained CCN4. Double fluorescent staining for CCN4 (red) and DNA (blue) was performed after fixation of TNF $\alpha$-stimulated pHCASMCs nucleofected with CRISPR control (left panel) or CRISPR TPM1 activation systems (right panel). TNF $\alpha 100 \mathrm{ng} / \mathrm{ml}$ refers to cells treated with rh TNF $\alpha$. (H) Fluorescence intensity of ICAM-1 measured in TNF $\alpha$-stimulated pHCASMCs nucleofected with CRISPR control or CRISPR TPM1 activation systems. ${ }^{* * *}$ refers to $p<0.0001$ as determined by unpaired $t$-test. (I) Fluorescence intensity of VCAM-1 measured in TNF $\alpha$-stimulated pHCASMCs nucleofected with CRISPR control or CRISPR TPM1 activation systems. ${ }^{\star \star \star \star}$ refers to $p<0.0001$ as determined by unpaired $t$-test. (J) Fluorescence intensity of p16 measured in nuclei of TNF $\alpha$-stimulated pHCASMCs nucleofected with CRISPR control or CRISPR TPM1 activation systems. ${ }^{\star \star \star \star}$ refers to $p<0.0001$ as determined by unpaired $t$-test. (K) Fluorescence intensity of NFKB measured in nuclei of TNF $\alpha$-stimulated pHCASMCs nucleofected with CRISPR control or CRISPR TPM1 activation systems. ${ }^{\star \star \star \star}$ refers to $p<0.0001$ as determined by unpaired $t$-test. (L) Fluorescence intensity of CCN4 measured in nuclei of TNF $\alpha$-stimulated pHCASMCs nucleofected with CRISPR control or CRISPR TPM1 activation systems.

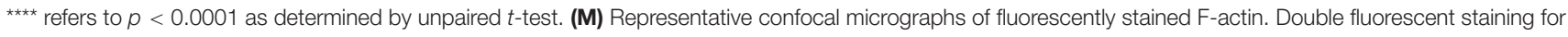
F-actin (green) and DNA (blue) was performed after fixation of TNF $\alpha$-stimulated pHCASMCs nucleofected with CRISPR control (left panel) or CRISPR TPM1 activation systems (right panel). TNF $\alpha 100 \mathrm{ng} / \mathrm{ml}$ refers to cells treated with $\mathrm{rh}$ TNF $\alpha$.

link between the cadherin- $\beta$-catenin complexes and F-actin (Thomas et al., 2013). Vinculin also protects VE-cadherincontaining AJs from opening during their force-induced remodeling (Huveneers et al., 2012). The rh TNF $\alpha$-independent and stable levels of vinculin in pHCAECs with activated TPM1 expression were supported by the lack of rh TNF $\alpha$-induced changes in $\alpha$-catenin and $\beta$-catenin levels (Figures 6G, $\mathbf{H}$ ). Furthermore, this was related with the rh TNF $\alpha$-independent expression of VE-cadherin and decreased level of cleaved VEcadherin (from $0.257 \pm 0.0163$ to $0.200 \pm 0.0031, p=0.0039$ ) (Figure 6I), suggesting that activation of endogenous expression of TPM1 leads to stabilization of AJs. Our further experiments showed that pHCAECs with activated transcription of TPM1 were able to form continuous AJs in the presence of $100 \mathrm{ng} / \mathrm{ml}$ rh $\mathrm{TNF} \alpha$. In contrast, rh $\mathrm{TNF} \alpha$ induced punctae appearance of AJs between the cells transfected with both CRISPR control and TPM1-knockout systems (Figure 7A). We also observed massive migracytosis after inflammatory activation of TPM1knockdown pHCAECs with $100 \mathrm{ng} / \mathrm{ml} \mathrm{rh}$ TNF $\alpha$ (Figures 7A,B). As shown in Figure 7C, force-dependent disorganization of cell-cell junctions was accompanied by the ability to form tubules on Matrigel. We observed a statistically significant 


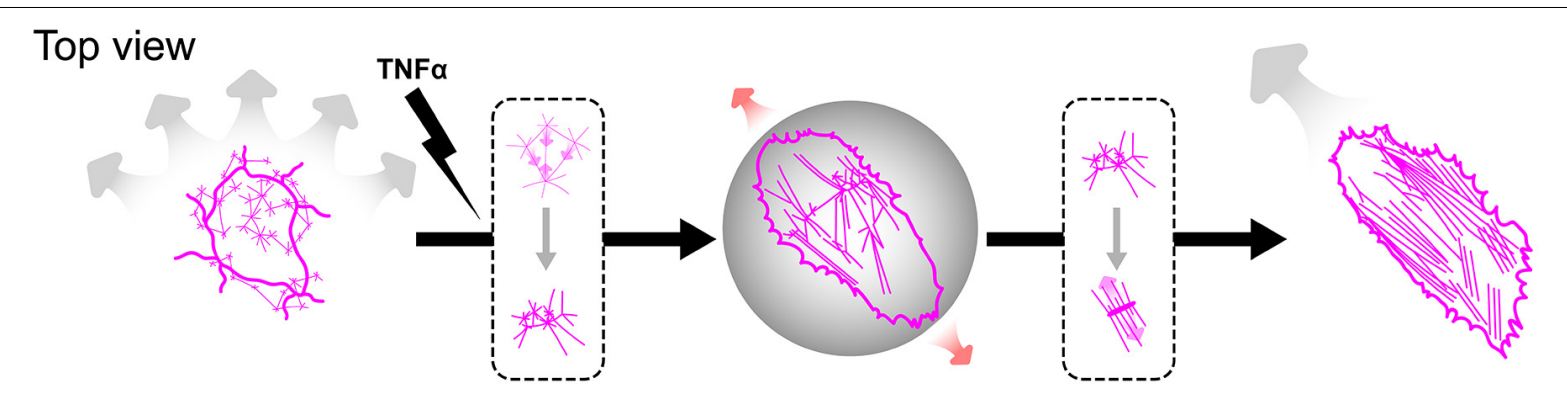

\section{Front view}
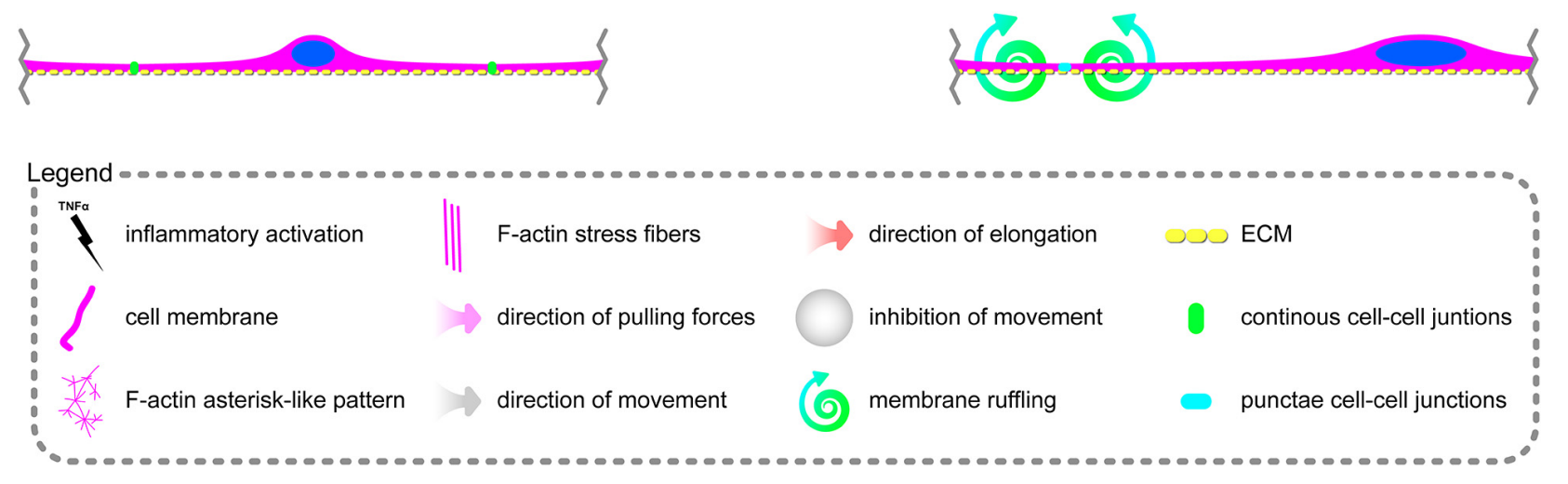

FIGURE 9 | Schematic overview of TNF $\alpha$-induced reorganization of F-actin and its effect on migration of pHCAECs.

increase in the number of tubules formed by rh TNF $\alpha$-activated pHCAECs with normal and downregulated expressions of TPM1, as compared to the cells with activated expression of TPM1 (from $58.50 \pm 3.391$ to $85.17 \pm 5.076, p=0.0011$, and $111.0 \pm 22.70, p=0.0022$, respectively, for the cells transfected with CRISPR TPM1 activation, control, and TPM1-knockdown systems; Figure 7D).

In summary, these data suggest that activation of endogenous expression of TPM1 inhibits inflammatory response of pHCAECs and downstream leads to the stabilization of cell-cell junctions through reducing the cleavage of VE-cadherin and maintaining stable levels of $\alpha$ - and $\beta$-catenins. Differently, CRISPRbased knockout of TPM1 leads to increased migracytosis in rh TNF $\alpha$-activated pHCAECs, which was confirmed by the increased angiogenic capacity of these cells in parallel with the formation of aggressive phenotypes. The migrative potential was also confirmed by the TNF $\alpha$-dependent increase in posttranslational expression of talin-2, vinculin, and $\beta$-catenin.

\section{Activation of Endogenous Expression of TPM1 Inhibits Tumor Necrosis Factor $\alpha$-Induced Activation, Proliferation, and Migration of Primary Human Coronary Artery Smooth Muscle Cells}

Because CRISPR-based activation of TPM1 expression resulted in the stabilization of interactions between pHCAECs treated with $100 \mathrm{ng} / \mathrm{ml} \mathrm{rh} \mathrm{TNF} \alpha$, we decided to evaluate whether the elevated level of $\alpha$-tropomyosin was able to affect pHCASMC response to rh TNF $\alpha$. As shown in Figures $\mathbf{8 A , B}$, transfection of pHCASMCs with CRISPR TPM1 activation system effectively upregulated expression of $\alpha$-tropomyosin in these cells. It has been shown that expression of both ICAM-1 and VCAM-1 on intimal and medial SMCs is prominent in fibrous plaques and advanced atherosclerotic lesions and that expression of VCAM-1 correlates with intimal neovessels and mononuclear cell infiltration (Kasper et al., 1996; O’Brien et al., 1996). Here, we observed that CRISPR-based activation of TPM1 inhibited the inflammatory response of pHCASMCs to $100 \mathrm{ng} / \mathrm{ml} \mathrm{rh}$ $\mathrm{TNF} \alpha$, as evidenced by reduced fluorescence of ICAM-1 and VCAM-1 (both $p<0.0001$; Figures 8C,D,H,I). Furthermore, we investigated the effect of rh $\mathrm{TNF} \alpha$ on functional nuclear markers of proliferation and migration of SMCs. We observed increased levels of nuclear fluorescence for p16 $(p<0.0001$; Figures 8E,J) and reduced fluorescence for nuclear NFKB and CCN4 (both $p<0.0001$ ) in TNF $\alpha$-activated pHCASMCs with upregulated expression of $\alpha$-tropomyosin, as compared to $\mathrm{TNF} \alpha$-activated cells transfected with the CRISPR control system (Figures $\mathbf{8 F , G , K , L ) . ~ T h e s e ~ o b s e r v a t i o n s ~ w e r e ~ c o n f i r m e d ~}$ by the analysis of F-actin organization. As shown in Figure $\mathbf{8 M}$, $\mathrm{TNF} \alpha$ promoted migrative distribution of the F-actin pattern in cells with normal expression of TPM1, whereas in pHCASMCs with CRISPR-based activation, expression of TPM1 supported a typical smooth muscle 'hill and valley' morphology.

In summary, these data suggest that activation of the endogenous expression of TPM1 inhibits inflammatory response of pHCASMCs and leads to the inhibition of their proliferation and migration. 


\section{Top view}

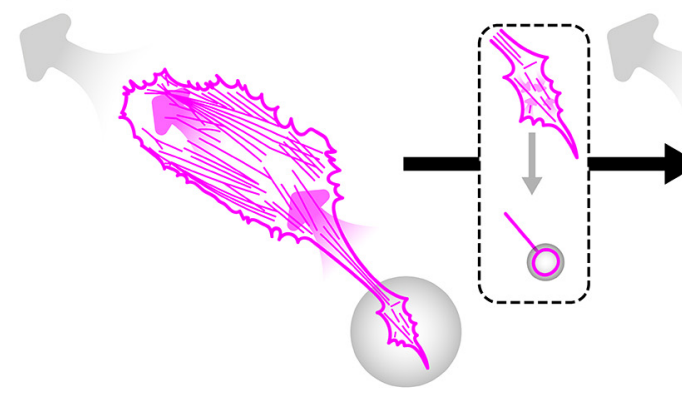

\section{Front view}
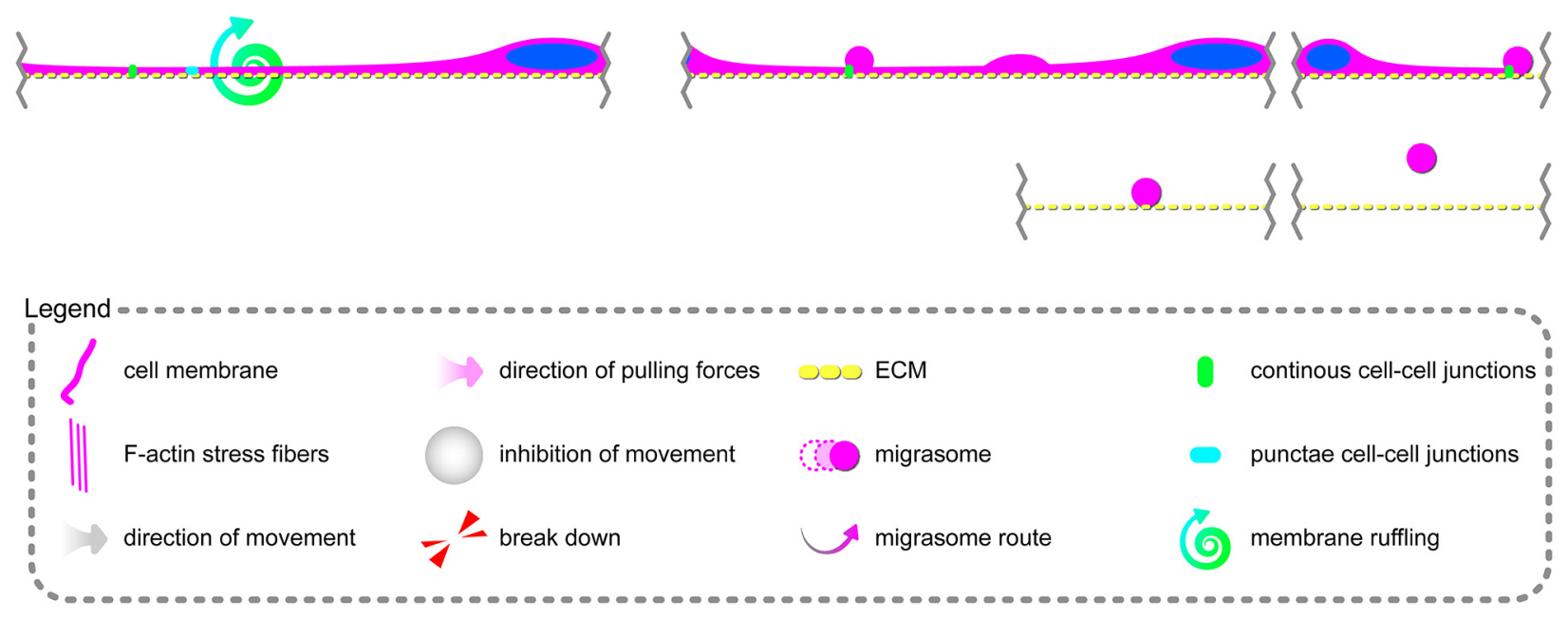

FIGURE 10 | Schematic overview of TNF $\alpha$-induced formation of migrasomes and migracytosis in pHCAECs.

\section{DISCUSSION}

The basis of inflammation is the changes in blood vessels allowing the recruitment of leukocytes to the site of damage. It results in vessel dilatation and an increase in their permeability (Libby, 2002). Inflammation is also an essential factor accompanying both the angiogenic and atherogenic pathways (Silvestre et al., 2008). The entire inflammatory process is mediated through cytokines. TNF $\alpha$ is one of the representatives of proinflammatory cytokines produced mainly by monocytes or monocyte-derived macrophages and affects many processes associated with the growth and characteristics of endothelial, smooth muscle, or immune system cells (Heller and Krönke, 1994; Peppel et al., 2005). A dual role of TNF $\alpha$ has been shown in the angiogenic response of endothelial cells: a proangiogenic effect in vivo and an antiangiogenic in vitro (Fràter-Schröder et al., 1987; Sainson et al., 2008). It has been also suggested that TNF $\alpha$ inhibits endothelial cell proliferation in vitro (Fràter-Schröder et al., 1987). The TNF $\alpha$ apoptotic response of human umbilical vein and aortic and coronary artery endothelial cells when cultured in vitro was also shown (Fràter-Schröder et al., 1987; Chen et al., 2004; Rastogi et al., 2012; Jiang et al., 2016). The reason for that can be a host organism used for the production of recombinant TNF $\alpha$. Escherichia coli is one of the organisms of choice for the production of recombinant proteins, such as $\mathrm{TNF} \alpha$, commonly used in vascular biology studies. However, protein expression in this system leads to many problems such as inclusion body formation related to incorrect disulfide bond formation, improper folding, or reduction in biological activity due to incomplete folding or mutations in cDNA (Rosano and Ceccarelli, 2014; Tavallaei et al., 2015). In the present study, we used rh TNF $\alpha$ produced in HEK293 cells, which effectively activated functional expression of E-selectin and VCAM-1 in pHCAECs. Although classical endothelial cell activation is defined by a shift in the expression of E-selectin, VCAM-1, and ICAM-1 (Gimbrone et al., 1997), we observed only a weak induction of functional expression of ICAM-1 (data not shown). Wu et al. (2004) indicated the heterogeneity of pHCAECs' response to TNF $\alpha$ stimulation, e.g., due to pathologic conditions of human coronary artery donors (Wu et al., 2004). However, it has been shown that soluble markers of endothelial injury are not uniformly increased in patients with documented coronary artery disease and that the plasma level of ICAM-1 did not allow identification of endothelial injury in such patients (Semaan et al., 2000). It was also suggested that the deficiency of ICAM-1 either alone or in combination with the deficiency of VCAM-1 did not alter nascent lesion formation, indicating the importance of VCAM-1 in the initiation of atherosclerosis 

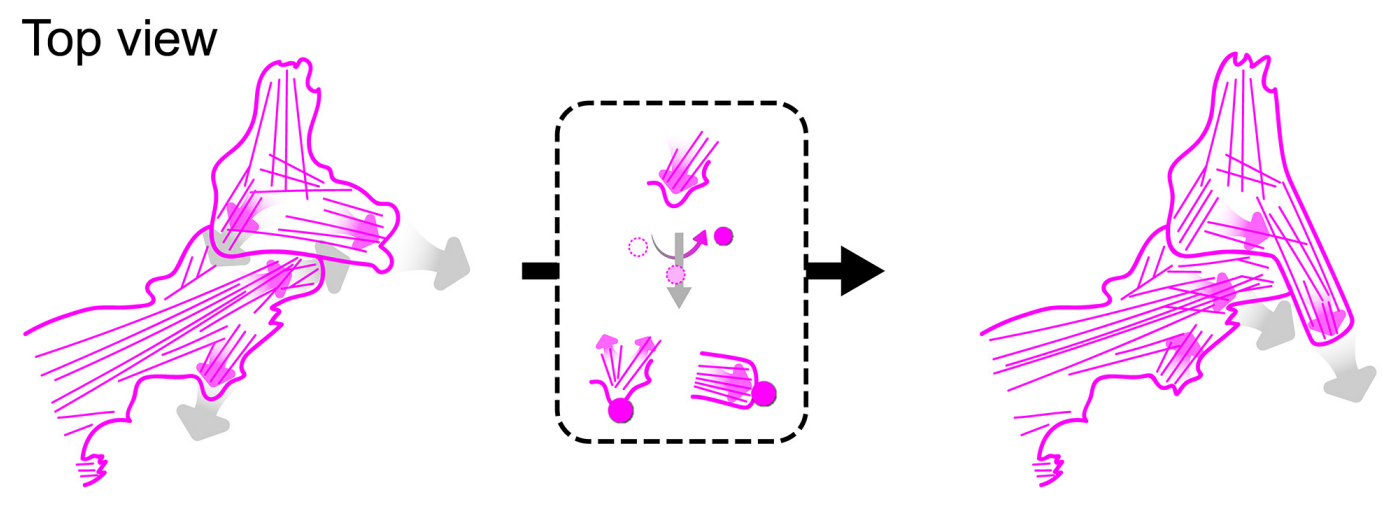

\section{Front view}
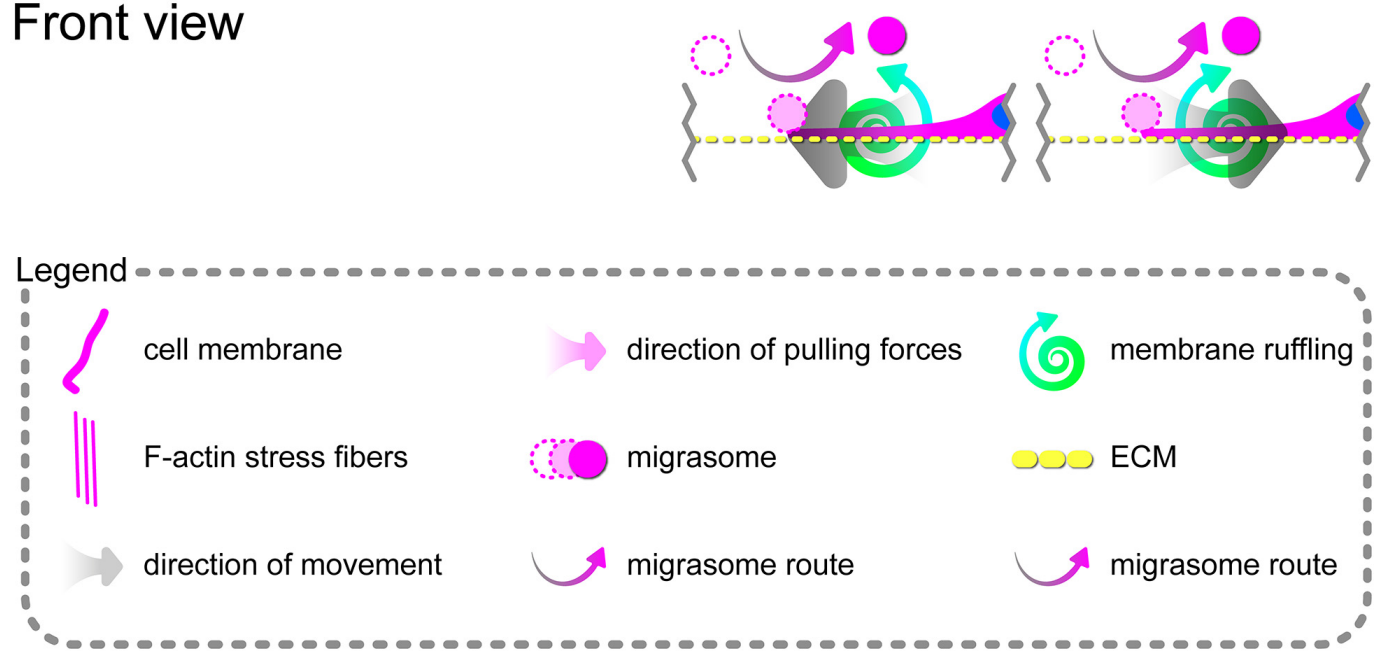

FIGURE 11 | Schematic overview of the mechanism of pHCAEC response to their interaction with migrasomes.

(Cybulsky et al., 2001). As the activation of endothelium is associated with enhanced interactions with leukocytes (Woodfin et al., 2009), we confirmed the flattening, firm adhesion, and further migration of Jurkat $\mathrm{T}$ cells on the surface of the rh TNF $\alpha$-activated pHCAECs. These data are consistent with the results received by Jaczewska et al. (2014) who demonstrated increased interactions between Jurkat $\mathrm{T}$ cells and HUVECs following treatment with INF- $\gamma$ or $\mathrm{TNF} \alpha$. In the course of the inflammatory process, the capture of leukocytes on the surface of the endothelium is possible due to the interaction of very late antigen-4 integrin on the leukocyte with selectins and VCAM-1 in endothelial cell walls (Abdala-Valencia et al., 2011). Similarly, the observed phenomenon of stronger adhesion of lymphocytes to endothelial monolayer was associated with increased expression of E-selectin and VCAM-1 cell adhesion molecules, which was also confirmed by Lu et al. (2016) and Munro et al. (1989). It was also suggested that the activation of endothelium includes not only changes in levels of adhesion molecules expression but also their redistribution from cell junctions to non-junctional membranes (JAM-A, JAM-C, and PECAM-1) or internalization from the plasma membrane (VEcadherin) (Reglero-Real et al., 2016). Additionally, the effect of
TNF $\alpha$ on TEM seems to depend on stimulation time. Within shorter stimulation times, leukocytes bind preferentially to the junctional regions of endothelial cells, whereas within longer periods, receptors in the junctional region are no longer easily available and TEM is intensified by cytoskeletal rearrangement and increased endothelial permeability (Jaczewska et al., 2014). Our observations seem to confirm this assumption since cytoskeletal rearrangement leading to the formation of discontinuous cell-cell junctions and intercellular gaps was finished at about $12-16 \mathrm{~h}$ from $\mathrm{rh} \mathrm{TNF} \alpha$ treatment.

Activation of pHCAECs following rh $\mathrm{TNF} \alpha$ treatment led to morphological changes. One of the most obvious was a transformation of the shape of the cells into a spindlelike one and oriented toward the direction of cell migration. Similar to that found in our study, TNF $\alpha$-induced spindleshaped, narrowed, and elongated morphology was observed in HUVECs and hCMEC/D3 cells and correlated with the increased paracellular permeability (Miyazaki et al., 2017; Ni et al., 2017). Here, we showed that rh TNF $\alpha$-induced change of the $\mathrm{pHCAEC}$ shape was related to the coordinated rearrangement of actin cytoskeleton from the star-like-shaped F-actin bundles into prominent, parallel-organized stress fibers. This perfectly 
explains the transition of polygonal cobblestone-like pHCAECs to a uniformly spindle-shaped and aligned monolayer. Asteror star-like-shaped structures were described by Fritzsche et al. (2017) as self-organized F-actin patterns, achieved by polarity sorting of actin filaments. In the in silico analysis, they showed two main nucleation pathways of this actin patterning. In the first scenario, Arp2/3 complexes bind to preexisting F-actin and nucleate new filaments from their pointed ends (-), leaving the barbed ends $(+)$ pointing outward. In the second one, myosin II crosslinks with F-actin at their barbed ends $(+)$ at the pattern centers, resulting in the point ends $(-)$ pointing outward (Fritzsche et al., 2017). In our study, the core of star-like-shaped F-actin structures co-localized with ARP2/3, whereas radiating bundles co-localized with NM myosin IIb and ROCK-1. Furthermore, the analysis of the trajectories of cells showed that the star-like-shaped organization of F-actin bundles determines the propensity of pHCAECs to cooperative migration in any direction, important in the effective contribution of barrier function. Differently, parallel-organized stress fibers in activated pHCAECs promoted directed and parallel motion during the coordinated migration (Figure 9). These results suggest that $\mathrm{rh} \mathrm{TNF} \alpha$ induces the formation of the aggressive angiogenic phenotype of pHCAECs, which was confirmed in various migratory experiments.

The transformation of the F-actin pattern induced by rh TNF $\alpha$ was closely related to abnormalities in junctional regions and the distribution of focal adhesion sites. We proved that $\mathrm{rh}$ TNF $\alpha$ promotes discontinuous cell-cell contact, preceded by membrane ruffling during polarization of $\mathrm{pHCAECs} \mathrm{to} \mathrm{achieve} \mathrm{a} \mathrm{spindle-like}$ shape promoting their migration. Interestingly, TNF $\alpha$-activated cells expressed NM myosin IIa, ARP 2/3 1B, and ROCK-1 in the regions of punctae cell-cell junctions. It was shown that NM myosin IIa controls cadherin clustering at AJs in a Rhodependent manner, allowing proper adhesion of epithelial cells (de Beco et al., 2012). Smutny et al. (2010) showed that NM myosin IIa promotes the accumulation of E-cadherin in the AJs while NM myosin IIB stabilizes the associated perijunctional actin ring, increasing cell-cell adhesion and preventing them from disruptive forces. However, Efimova and Svitkina (2018) showed an association of NM myosin IIa with contractile actin bundle running parallel to linear AJs in endothelial cells. In our study, the NM myosin IIa correlated with a bright fluorescence of $\mathrm{AJ}$ and TJ proteins in the regions of punctae cell-cell junctions. Furthermore, we showed oligomerization of claudin-5 in activated pHCAECs. Claudin -5 preferentially forms hexamers, which make cell contacts much stronger than in the case of the monomeric form (Krause et al., 2008). Considering the above, this suggests that $\mathrm{rh} \mathrm{TNF} \alpha$-induced punctae intercellular junctions are strong and play an important role in directed cell migration of pHCAECs, allowing follower cells to trail the leaders (Ozawa et al., 2020).

Ma et al. (2015) identified and described extracellular membrane-bounded vesicular structures that are characteristically generated along retraction fibers in migrating cells. They named these pomegranate-like structures as migrasomes and showed their formation in various cell lines, including MEF (mouse embryonic fibroblast), NIH3T3 (mouse embryonic fibroblast), HaCaT (human keratinocyte), MDA-MB231 (human breast cancer), HCT116 (human colon cancer), SW480 (human adenocarcinoma), MGC803 (human gastric carcinoma), SKOV-3 (human ovarian adenocarcinoma), and B16 (mouse melanoma), and organs, such as the eye, lung, and intestine. These structures have been also observed in the lumen of blood vessels or pulmonary alveoli (Ma et al., 2015). However, the mechanism of their formation and biological or clinical importance is still unknown. Huang et al. (2019) proposed the mechanism of migrasome growing as an assembly of tetraspanin- and cholesterol-enriched membrane microdomains into micron-scale macrodomains. It has been also shown that tetraspanins are localized at digitation junctions, which reflect the transition processes before the establishment or after the disassembly of stable cell-cell junctions (Huang et al., 2018). Here, we showed intensified formation of migrasomes in TNF $\alpha$-stimulated pHCAECs and that their formation is highly dependent on cell-cell and cell-ECM interaction, suggesting their role in the transmission of F-actin-based mechanical forces for proper polarization of adjacent cells and coordination of the cell migration direction. Furthermore, we frequently observed their release by breaking the retraction fibers, which resulted in their stay at points of cell-cell and/or cell-ECM contact as well as their release to the cell culture medium (Figure 10). Finally, we showed that floating migrasomes exert local cytoskeletal rearrangement and motility response (Figure 11), suggesting their involvement in intercellular signalization promoting directed migration of activated pHCAECs.

The data presented here showed that rh TNF $\alpha$ induces F-actin reorganization resulting in mechanical disruption of cell-cell junction continuity through the promotion of directed migration of pHCAECs. In this case, methods for regulation of the actin cytoskeleton structure might be clinically potent. One of such targets may be $\alpha$-tropomyosin, which belongs to a family of actin-binding proteins. Tropomyosins are coiledcoil parallel dimers that form a head-to-tail polymer along the length of actin filaments regulating their access of other actinbinding proteins (Gunning et al., 2015). In mammals, over 40 tropomyosin isoforms are produced by alternative promoter selection, alternative splicing and/or $3^{\prime}$ end processing of four different genes: TPM1, TPM2, TPM3, and TPM4 (Denz et al., 2004). Tropomyosin variants are classified into two major groups: high molecular weight (HMW; $\sim 284$ amino acids and molecular weight between 33 and $40 \mathrm{kDa}$ ) and low molecular weight (LMW; $\sim 247$ amino acids and molecular weight between 28 and $34 \mathrm{kDa}$ ) (Schevzov et al., 2011). In muscle cells, all actin filaments are saturated with tropomyosins and regulate muscle contraction in a calcium-dependent manner, while in non-muscle cells, saturation of actin vary from $30 \%$ to $90 \%$, depending on the cell type and tropomyosins stabilize the actin cytoskeleton and participate in many cellular processes, including motility, cell-cell adhesion, and cell-extracellular interactions (Perry, 2001; Humayun-Zakaria et al., 2019; Janco et al., 2019). Our previous studies have shown that increased expression of $\alpha$-tropomyosin protects endothelial integrity against Lhomocysteine and cigarette smoke extract in EA.hy926 (Gagat et al., 2013, 2014) and preserves transformed alveolar epithelial 
cell-cell junctions against disintegration induced by cigarette smoke extract (Gagat et al., 2016). $\alpha$-Tropomyosin was also indicated to function as a tumor suppressor primarily by inhibiting cell proliferation, angiogenesis, and metastasis in renal cell carcinoma (Wang et al., 2019). Here, we showed that CRISPR-based activation of the endogenous expression of TPM1 inhibits the inflammatory response of pHCAECs to $\mathrm{TNF} \alpha$ and leads to the stabilization of cell-cell junctions through reduced cleavage of $\mathrm{VE}$-cadherin and the maintenance of the stable levels of $\alpha$ - and $\beta$-catenins. We also showed that CRISPR-based knockout of TPM1 leads to an increased angiogenic capacity of rh TNF $\alpha$-activated pHCAECs and augments the formation of migrasomes and migracytosis in these cells. These findings pushed us to question how pHCASMCs with the activated expression of TPM1 will respond to rh TNF $\alpha$. Wang et al. (2011) showed that TPM1 is a validated target of microRNA-21, which negatively regulates its posttranslational expression and leads to arteriosclerosis obliterans. They also showed that overexpression of TPM1 decreased proliferation and migration of hASMCs, whereas its silencing significantly attenuated the antiproliferative and anti-migratory roles of the miR-21 inhibitor (Wang et al., 2011). Our results indicate that CRISPR-based activation of TPM1 expression results in inhibition of the inflammatory response of pHCASMCs and exerts antiproliferative and anti-migratory activity.

Our study has several limitations. First of all, the study was performed in static conditions. However, the effect of rh TNF $\alpha$ is similar to that in in vivo studies, showing the proangiogenic action of $\mathrm{TNF} \alpha$. Also, due to the study design, we did not perform migratory tests on different ECM proteins, but we showed a lack of differences in the organization of F-actin in rh TNF $\alpha$-activated pHCAECs when cultured on fibronectin, laminin, collagen I, and collagen IV coatings. Proliferation and migration of TNF $\alpha$-activated pHCASMCs were also assessed based on the nuclear localization and fluorescence intensity of p16, NFкB, and CCN4. Furthermore, our study is based on morphological and semiquantitative analyses, but it allows for fast and easy translation of the findings into applied clinical studies. Finally, we used commercially available pHCAECs and pHCASMCs. Although we know the cause of the death of cell donors, we cannot unequivocally exclude that there was no generalized shock reaction of unknown duration that could affect the studied cells. In order to exclude this possible and reversible effect, only cells within three to four passages were used for all the experiments. It is also worth remembering that TPM1 gene products occur in at least 29 isoforms (Cooley and Bergtrom, 2001). Unfortunately, in our study, we were unable to identify the isoform targeted by the applied CRISPR systems. Identification of the specific isoform, the expression of which determines the observed effect, is extremely important in the context of subsequent studies and their clinical application. However, in our study, tropomyosin was detected using the F-6 antibody (Santa Cruz) specific for an epitope mapping between amino acids 123 and 161. Furthermore, the molecular weight of the detected isoform of tropomyosin was in the range $33-35 \mathrm{kDa}$ in pHCAECs and $33-34 \mathrm{kDa}$ in $\mathrm{pHCASMCs}$.
In conclusion, the present investigations demonstrated that rh $\mathrm{TNF} \alpha$-induced activation of pHCAECs results in actin cytoskeleton reorganization, promoting their directed and coordinated migration. We also proposed that the formation and release of migrasomes are highly related to increased adhesion and junctional strength of tips of retraction fibers with adjacent cells and that they play a role in intercellular signalization promoting directed cell migration. Furthermore, we showed that stabilization of F-actin through the activation of endogenous expression of TPM1 inhibits inflammatory response of pHCAECs, allowing formation of continuous cellcell junctions, and exerts antiproliferative and anti-migratory effects in pHCASMCs. Additional in vivo studies are needed to gain a better understanding of the role of $\alpha$-tropomyosin in atherosclerosis and angiogenesis, as well as to examine the potential of TPM1 as a candidate therapy target for proinflammatory vascular disorders. However, our findings may be adapted during the design and development of new coronary stent devices.

\section{DATA AVAILABILITY STATEMENT}

The original contributions presented in the study are included in the article/Supplementary Material, further inquiries can be directed to the corresponding author.

\section{AUTHOR CONTRIBUTIONS}

MG and AG conceptualized the project and designed the experiments. MG, WZ, KM, and AK performed the experiments. MG and DG interpreted the results. $\mathrm{MG}, \mathrm{KM}$, and $\mathrm{WZ}$ performed image analysis. MG and $\mathrm{WZ}$ performed statistical analysis. MG and WZ drafted the manuscript. KM and DG edited the manuscript. AK-W and JZ critically reviewed the manuscript. MG gained funding for the study. AG provided supervision. All authors contributed to the article and approved the submitted version.

\section{FUNDING}

This study was supported by grant no. 2015/17/D/NZ7/00809 to MG from National Science Centre, Poland.

\section{ACKNOWLEDGMENTS}

The authors are grateful to Magdalena Izdebska and Marta HałasWiśniewska for sharing technical expertise.

\section{SUPPLEMENTARY MATERIAL}

The Supplementary Material for this article can be found online at: https://www.frontiersin.org/articles/10.3389/fcell.2021. 668032/full\#supplementary-material 
Supplementary Figure S1 | TNF $\alpha$-induced expression of E-selectin in pHCAECs. Triple fluorescent staining for E-selectin (green), F-actin (red), and DNA (blue) was performed after fixation. CTRL refers to the control (top panel), TNF $\alpha 100 \mathrm{ng} / \mathrm{ml}$ to cells treated with rh TNF $\alpha$.

Supplementary Figure S2 I TNF $\alpha$-induced expression of VCAM-1 in pHCAECs (A) Representative micrographs of intravital detection of VCAM-1 using magnetic beads coated with anti-VCAM-1 monoclonal antibodies (bright field). F-actin (red) and nuclei (blue) were stained fluorescently after fixation. TNF $\alpha 100 \mathrm{ng} / \mathrm{ml}$ refers to cells treated with rh TNF $\alpha, m A b$ to monoclonal antibodies. (B) Representative confocal micrograph of fluorescently stained VCAM-1. Triple fluorescent staining for VCAM-1 (green), F-actin (red), and DNA (blue) was performed after fixation. $\mathrm{TNF} \alpha 100 \mathrm{ng} / \mathrm{ml}$ refers to cells treated with rh TNF $\alpha$. (C) Representative micrographs of adherent Jurkat $T$ cells (contrast phase and fluorescence) after 30 min of their co-culture with pHCAECs (contrast phase). Nuclei of Jurkat cells (blue) were stained with Hoechst 33342. CTRL refers to the control (top panel), $\mathrm{TNF} \alpha 100 \mathrm{ng} / \mathrm{ml}$ to cells treated with $\mathrm{rh} \mathrm{TNF} \alpha$ (bottom panel).

Supplementary Figure S3 | Effect of TNF $\alpha$ on migration of pHCAECs. (A) Rose plot presenting direction bias of pHCAEC migration in confluence within $36 \mathrm{~h}$. CTRL refers to the control (left panel), TNF $\alpha 100 \mathrm{ng} / \mathrm{ml}$ to cells treated with $\mathrm{rh}$ TNF $\alpha$ (right panel), ${ }^{* *}$ to $p<0.01$, $^{* * *}$ to $p<0.0001$, as determined by Rayleigh test. (B) Euclidean distance of pHCAECs during 36-h migration in $100 \%$ confluence. CTRL refers to the control, TNF $\alpha 100 \mathrm{ng} / \mathrm{ml}$ to cells treated with $\mathrm{rh}$ TNF $\alpha$, NS to non-significant to the control, as determined by unpaired $t$-test. (C) Accumulated distance of pHCAECs during 36-h migration in 100\% confluence. CTRL refers to the control, TNF $\alpha 100 \mathrm{ng} / \mathrm{ml}$ to cells treated with $\mathrm{rh}$ TNF $\alpha$, ${ }^{* * * *}$ to $p<0.0001$, as determined by unpaired $t$-test. (D) Velocity of pHCAECs during 36-h migration in $100 \%$ confluence. CTRL refers to the control, TNF $\alpha 100 \mathrm{ng} / \mathrm{ml}$ to cells treated with $\mathrm{rh} T \mathrm{TF} \alpha,{ }^{* * * *}$ to $p<0.0001$, as determined by unpaired $t$-test. (E) Correlation between Euclidean distance of pHCAECs and time during 36-h migration in $100 \%$ confluence. CTRL refers to the control, TNF $\alpha 100 \mathrm{ng} / \mathrm{ml}$ to cells treated with rh TNF $\alpha$, NS to non-significant, ${ }^{* *}$ to $p<0.01$, as determined by Pearson's correlation coefficient analysis. (F) Correlation between accumulated distance of pHCAECs and time during 36-h migration in 100\% confluence. CTRL refers to the control, TNF $\alpha 100 \mathrm{ng} / \mathrm{ml}$ to cells treated with $\mathrm{rh}$ TNF $\alpha$, NS to non-significant, ${ }^{* *}$ to $p<0.01$, as determined by Pearson's correlation coefficient analysis. (G) Correlation between velocity of pHCAECs and time during $36-\mathrm{h}$ migration in $100 \%$ confluence. CTRL refers to the control, TNF $\alpha 100 \mathrm{ng} / \mathrm{ml}$ to cells treated with rh TNF $\alpha$, NS to non-significant, $* *$ to $p<0.01$, as determined by Pearson's correlation coefficient analysis. (H) Correlation between time, accumulated distance, Euclidean distance or velocity, and directness of control pHCAECs during 36-h migration in 100\% confluence. CTRL refers to the control, NS to non-significant, ${ }^{* * * *}$ to $p<0.0001$. (I) Correlation between time, accumulated distance, Euclidean distance or velocity, and directness of TNF $\alpha$ pHCAECs during 36-h migration in 100\% confluence. TNF $\alpha 100 \mathrm{ng} / \mathrm{ml}$ refers to cells treated with rh TNF $\alpha$, NS to non-significant, ${ }^{*}$ to $p<0.05$, **** to $p<0.0001$. (J) Representative contrast phase micrograph presenting pHCAEC migration to the wound site. Curves indicate leading edge of migrating cells, arrows the direction of the movement. CTRL refers to the control (left panel), TNF $\alpha$ $100 \mathrm{ng} / \mathrm{ml}$ to cells treated with $\mathrm{rh}$ TNF $\alpha$ (right panel). (K) Representative contrast phase micrograph presenting pHCAEC migration to the open field. Curves indicate leading edge of migrating cells, arrows the direction of the movement. CTRL refers to the control (left panel), TNF $\alpha 100 \mathrm{ng} / \mathrm{ml}$ to cells treated with $\mathrm{rh}$ TNF $\alpha$ (right panel). (L) Number of pHCAECs migrated through $3-\mu \mathrm{m}$ pores per microscopic field. CTRL refers to the control, TNF $\alpha 100 \mathrm{ng} / \mathrm{ml}$ to cells treated with rh TNF $\alpha$, **** to $p<0.0001$, as determined by unpaired $t$-test. (M) Number of tubes per microscopic field formed by pHCAECs on Matrigel after 3, 6, and $12 \mathrm{~h}$ after seeding. CTRL refers to the control, TNF $\alpha 100 \mathrm{ng} / \mathrm{ml}$ to cells treated with $\mathrm{rh}$ TNF $\alpha,{ }^{*}$ to $p<0.05,{ }^{* * * *}$ to $p<0.0001$, as determined by Kruskal-Wallis test, $\$ \$ \$$ to $p<0.0001$, as determined by unpaired $t$-test.

Supplementary Figure S4 I Effect of rh TNF $\alpha$ on adhesion of pHCAECs during initial $4 \mathrm{~h}$ from the seeding. (A) Number of adherent pHCAECs per microscopic field from the control and TNF $\alpha$-activated pHCAECs. (B) Representative micrographs of adherent pHCAECs (contrast phase) within $4 \mathrm{~h}$ after seeding. CTRL refers to the control (top panel), TNF $\alpha 100 \mathrm{ng} / \mathrm{ml}$ to cells treated with $\mathrm{rh}$ TNF $\alpha$ (bottom panel). (C) Relative number of adherent pHCAECs per microscopic field from the control and TNF $\alpha$-activated pHCAECs after $0.5 \mathrm{~h}$ from seeding. NS refers to non-significant to the control, as determined by unpaired $t$-test. (D)
Relative number of adherent pHCAECs per microscopic field from the control and TNF $\alpha$-activated pHCAECs after $1 \mathrm{~h}$ from seeding. ** refers to $p<0.01$, as determined by unpaired $t$-test. (E) Relative number of adherent pHCAECs per microscopic field from the control and TNF $\alpha$-activated pHCAECs after $2 \mathrm{~h}$ from seeding. ${ }^{*}$ refers to $p<0.05$, as determined by unpaired $t$-test. (F) Relative number of adherent pHCAECs per microscopic field from the control and TNF $\alpha$-activated pHCAECs after $2 \mathrm{~h}$ from seeding. * refers to $p<0.05$, as determined by unpaired $t$-test.

Supplementary Figure S5 | Effect of rh TNF $\alpha$ on organizational pattern of F-actin in pHCAECs cultured on different ECM coatings. (A) Representative confocal micrograph of fluorescently stained F-actin in pHCAECs cultured on fibronectin. Double fluorescent staining for F-actin (green) and DNA (blue) was performed after fixation. CTRL refers to the control (left panel), TNF $\alpha 100 \mathrm{ng} / \mathrm{ml}$ to cells treated with rh TNF $\alpha$ (right panel). (B) Representative confocal micrograph of fluorescently stained F-actin in pHCAECs cultured on fibronectin. Double fluorescent staining for F-actin (red) and DNA (blue) was performed after fixation. CTRL refers to the control (left panel), TNF $\alpha 100 \mathrm{ng} / \mathrm{ml}$ to cells treated with $\mathrm{rh}$ TNF $\alpha$ (right panel). (C) Representative confocal micrograph of fluorescently stained F-actin in pHCAECs cultured on laminin. Double fluorescent staining for F-actin (green) and DNA (blue) was performed after fixation. CTRL refers to the control (left panel), TNF $\alpha$ $100 \mathrm{ng} / \mathrm{ml}$ to cells treated with rh TNF $\alpha$ (right panel), EHS to

Engelbreth-Holm-Swarm. (D) Representative confocal micrograph of fluorescently stained F-actin in pHCAECs cultured on laminin. Double fluorescent staining for F-actin (red) and DNA (blue) was performed after fixation. CTRL refers to the control (left panel), TNF $\alpha 100 \mathrm{ng} / \mathrm{ml}$ to cells treated with rh TNF $\alpha$ (right panel), EHS to Engelbreth-Holm-Swarm. (E) Representative confocal micrograph of fluorescently stained F-actin in pHCAECs cultured on collagen I. Double fluorescent staining for F-actin (green) and DNA (blue) was performed after fixation. CTRL refers to the control (left panel), TNF $\alpha 100 \mathrm{ng} / \mathrm{ml}$ to cells treated with rh TNF $\alpha$ (right panel). (F) Representative confocal micrograph of fluorescently stained F-actin in pHCAECs cultured on collagen I. Double fluorescent staining for F-actin (red) and DNA (blue) was performed after fixation. CTRL refers to the control (left panel), TNF $\alpha 100 \mathrm{ng} / \mathrm{ml}$ to cells treated with rh TNF $\alpha$ (right panel). (G) Representative confocal micrograph of fluorescently stained F-actin in pHCAECs cultured on collagen IV. Double fluorescent staining for F-actin (green) and DNA (blue) was performed after fixation. CTRL refers to the control (left panel), TNF $\alpha$ $100 \mathrm{ng} / \mathrm{ml}$ to cells treated with $\mathrm{rh}$ TNF $\alpha$ (right panel), EHS to

Engelbreth-Holm-Swarm. (H) Representative confocal micrograph of fluorescently stained F-actin in pHCAECs cultured on collagen IV. Double fluorescent staining for F-actin (red) and DNA (blue) was performed after fixation. CTRL refers to the control (left panel), TNF $\alpha 100 \mathrm{ng} / \mathrm{ml}$ to cells treated with rh TNF $\alpha$ (right panel), EHS to Engelbreth-Holm-Swarm.

Supplementary Video S1 | Migration of Jurkat T cells on the surface of pHCAECs. CTRL refers to the control (upper panel), TNF $\alpha 100 \mathrm{ng} / \mathrm{ml}$ to cells treated with rh TNF $\alpha$ (lower panel). Nuclei of Jurkat cells were stained with Hoechst 33342. Time-lapse images were acquired for 2 min at 3.33-s intervals after 30 min from co-culture of pHCAECs (contrast phase) with counterstained Jurkat cells (contrast phase and fluorescence). Frame rate, 10 frames/s.

Supplementary Video S2 I TNF $\alpha$-induced changes in migration of pHCAECs to the wound site. CTRL refers to the control (upper panel), TNF $\alpha 100 \mathrm{ng} / \mathrm{ml}$ to cells treated with TNF $\alpha$ (lower panel). Time-lapse images were acquired for $24 \mathrm{~h}$ at 10-min intervals. Frame rate, 20 frames/s.

Supplementary Video S3 I TNF $\alpha$-induced changes in migration of pHCAECs to the open field. CTRL refers to the control (upper panel), TNF $\alpha 100 \mathrm{ng} / \mathrm{ml}$ to cells treated with TNF $\alpha$ (lower panel). Time-lapse images were acquired for $24 \mathrm{~h}$ at 10-min intervals. Frame rate, 20 frames/s.

Supplementary Video S4 | TNF $\alpha$-induced changes in the ability of pHCAECs to form tubes on Matrigel. CTRL refers to the control (left panel), TNF $\alpha 100 \mathrm{ng} / \mathrm{ml}$ to cells treated with $\mathrm{rh}$ TNF $\alpha$ (right panel). Time-lapse images were acquired for $24 \mathrm{~h}$ at 10-min intervals. Frame rate, 20 frames/s.

Supplementary Video S5 | TNF $\alpha$-induced changes in organization pattern of F-actin and distribution of focal adhesion sites. Actin-GFP (red) and talin-RFP (green) were expressed using baculoviruses. TNF $\alpha 100 \mathrm{ng} / \mathrm{ml}$ refers to cells treated with $\mathrm{rh}$ TNF $\alpha$. Time-lapse images were acquired for $18 \mathrm{~h}$ at $10-\mathrm{min}$ intervals after $2 \mathrm{~h}$ from treatment. Frame rate, 20 frames/s. 
Supplementary Video S6 | TNF $\alpha$-induced formation of migrasomes and migracytosis. Actin-GFP (red) and talin-RFP (green) were expressed using baculoviruses. TNF $\alpha 100 \mathrm{ng} / \mathrm{ml}$ refers to cells treated with $\mathrm{rh}$ TNF $\alpha$. Time-lapse images were acquired for $6.5 \mathrm{~h}$ at 10 -min intervals after $15 \mathrm{~h}$ from treatment. Frame rate, 3 frames/s.

\section{REFERENCES}

Abdala-Valencia, H., Berdnikovs, S., and Cook-Mills, J. M. (2011). Mechanisms for vascular cell adhesion molecule-1 activation of ERK1/2 during leukocyte transendothelial migration. PLoS One 6:e26706. doi: 10.1371/journal.pone. 0026706

Austen, K., Ringer, P., Mehlich, A., Chrostek-Grashoff, A., Kluger, C., Klingner, C., et al. (2015). Extracellular rigidity sensing by talin isoform-specific mechanical linkages. Nat. Cell Biol. 17, 1597-1606. doi: 10.1038/ncb3268

Bhadriraju, K., Yang, M., Alom Ruiz, S., Pirone, D., Tan, J., and Chen, C. S. (2007). Activation of ROCK by RhoA is regulated by cell adhesion, shape, and cytoskeletal tension. Exp. Cell Res. 313, 3616-3623. doi: 10.1016/j.yexcr.2007. 07.002

Birukova, A. A., Shah, A. S., Tian, Y., Moldobaeva, N., and Birukov, K. G. (2016). Dual role of vinculin in barrier-disruptive and barrier-enhancing endothelial cell responses. Cell Signal. 28, 541-551. doi: 10.1016/j.cellsig.2016.02.015

Canver, A. C., Ngo, O., Lownes Urbano, R., and Morss Clynedoi, A. (2016). Endothelial directed collective migration depends on substrate stiffness via localized myosin contractility and cell-matrix interactions. J. Biomech. 49, 1369-1380. doi: 10.1016/j.jbiomech.2015.12.037

Cerutti, C., and Ridley, A. J. (2017). Endothelial cell-cell adhesion and signaling. Exp. Cell Res. 358, 31-38. doi: 10.1016/j.yexcr.2017.06.003

Chen, J., Li, D., Zhang, X., and Mehta, J. L. (2004). Tumor necrosis factor-alphainduced apoptosis of human coronary artery endothelial cells: modulation by the peroxisome proliferator-activated receptor-gamma ligand pioglitazone. J. Cardiovasc. Pharmacol. Ther. 9, 35-41. doi: 10.1177/107424840400900i106

Chistiakov, D. A., Orekhov, A. N., and Bobryshev, Y. V. (2015). Endothelial barrier and its abnormalities in cardiovascular disease. Front Physiol. 6:365. doi: 10 3389/fphys.2015.00365

Cooley, B. C., and Bergtrom, G. (2001). Multiple combinations of alternatively spliced exons in rat tropomyosin-alpha gene mRNA: evidence for 20 new isoforms in adult tissues and cultured cells. Arch. Biochem. Biophys. 390, 71-77. doi: 10.1006/abbi.2001.2347

Cybulsky, M. I., Iiyama, K., Li, H., Zhu, S., Chen, M., Iiyama, M., et al. (2001). A major role for VCAM-1, but not ICAM-1, in early atherosclerosis. J. Clin. Invest. 107, 1255-1262. doi: 10.1172/JCI11871

de Beco, S., Amblard, F., and Coscoy, S. (2012). New insights into the regulation of E-cadherin distribution by endocytosis. Int. Rev. Cell Mol. Biol. 295, 63-108. doi: 10.1016/B978-0-12-394306-4.00008-3

Denz, C. R., Narshi, A., Zajdel, R. W., and Dube, D. K. (2004). Expression of a novel cardiac-specific tropomyosin isoform in humans. Biochem. Biophys. Res. Commun. 320, 1291-1297. doi: 10.1016/j.bbrc.2004.06.084

Efimova, N., and Svitkina, T. M. (2018). Branched actin networks push against each other at adherens junctions to maintain cell-cell adhesion. J. Cell Biol. 217, 1827-1845. doi: 10.1083/jcb.201708103

Fràter-Schröder, M., Risau, W., Hallmann, R., Gautschi, P., and Böhlen, P. (1987). Tumor necrosis factor type alpha, a potent inhibitor of endothelial cell growth in vitro, is angiogenic in vivo. Proc. Natl. Acad. Sci. U.S.A. 84, 5277-5281. doi: 10.1073/pnas.84.15.5277

Fritzsche, M., Li, D., Colin-York, H., Chang, V. T., Moeendarbary, E., Felce, J. H., et al. (2017). Self-organizing actin patterns shape membrane architecture but not cell mechanics. Nat. Commun. 8:14347. doi: 10.1038/ncomms14347

Gagat, M., Grzanka, D., Izdebska, M., and Grzanka, A. (2013). Effect of L-homocysteine on endothelial cell-cell junctions following F-actin stabilization through tropomyosin-1 overexpression. Int. J. Mol. Med. 32, 115-129. doi: 10.3892/ijmm.2013.1357

Gagat, M., Grzanka, D., Izdebska, M., Sroka, W. D., Hałas-Wiśniewska, M., and Grzanka, A. (2016). Tropomyosin-1 protects transformed alveolar epithelial cells against cigaret smoke extract through the stabilization of F-actindependent cell-cell junctions. Acta Histochem. 118, 225-235. doi: 10.1016/j. acthis.2016.01.003
Supplementary Video S7 | Interactions of pHCAECs with migrasome released to cell culture medium. Actin-GFP (green) and talin-RFP (red) were expressed using baculovirus system. TNF $\alpha 100 \mathrm{ng} / \mathrm{ml}$ refers to cells treated with rh TNF $\alpha$. Time-lapse images were acquired for $1.25 \mathrm{~h}$ at 5 -min intervals after $18 \mathrm{~h}$ from treatment. Frame rate, 3 frames/s.

Gagat, M., Grzanka, D., Izdebska, M., Sroka, W. D., Marszałł, M. P., and Grzanka, A. (2014). Tropomyosin-1 protects endothelial cell-cell junctions against cigarette smoke extract through F-actin stabilization in EA.hy926 cell line. Acta Histochem. 116, 606-618. doi: 10.1016/j.acthis.2013.11.013

Gimbrone, M. A. Jr., and García-Cardeña, G. (2016). Endothelial cell dysfunction and the pathobiology of atherosclerosis. Circ. Res. 118, 620-636. doi: 10.1161/ CIRCRESAHA.115.306301

Gimbrone, M. A. Jr., Resnick, N., Nagel, T., Khachigian, L. M., Collins, T., and Topper, J. N. (1997). Hemodynamics, endothelial gene expression, and atherogenesis. Ann. N. Y. Acad. Sci. 811, 1-10. doi: 10.1111/j.1749-6632.1997. tb51983.x

Godo, S., and Shimokawa, H. (2017). Endothelial functions. Arterioscler. Thromb. Vasc. Biol. 37, e108-e114. doi: 10.1161/ATVBAHA.117.309813

Gunning, P. W., Hardeman, E. C., Lappalainen, P., and Mulvihill, D. P. (2015). Tropomyosin - master regulator of actin filament function in the cytoskeleton. J. Cell. Sci. 128, 2965-2974. doi: 10.1242/jcs.172502

Heller, R. A., and Krönke, M. (1994). Tumor necrosis factor receptormediated signaling pathways. J. Cell Biol. 126, 5-9. doi: 10.1083/jcb.126. 1.5

Huang, C., Fu, C., Wren, J. D., Wang, X., Zhang, F., Zhang, Y. H., et al. (2018). Tetraspanin-enriched microdomains regulate digitation junctions. Cell. Mol. Life Sci. 75, 3423-3439. doi: 10.1007/s00018-018-2803-2

Huang, Y., Zucker, B., Zhang, S., Elias, S., Zhu, Y., and Chen, H. (2019). Migrasome formation is mediated by assembly of micron-scale tetraspanin macrodomains. Nat. Cell Biol. 21, 991-1002. doi: 10.1038/s41556-019-0367-5

Humayun-Zakaria, N., Arnold, R., Goel, A., Ward, D., Savill, S., and Bryan, R. T. (2019). Tropomyosins: potential biomarkers for urothelial bladder cancer. Int. J. Mol. Sci. 20:1102. doi: 10.3390/ijms20051102

Huveneers, S., Oldenburg, J., Spanjaard, E., van der Krogt, G., Grigoriev, I., Akhmanova, A., et al. (2012). Vinculin associates with endothelial VE-cadherin junctions to control force-dependent remodeling. J. Cell Biol. 196, 641-652. doi: $10.1083 /$ jcb. 201108120

Jaczewska, J., Abdulreda, M. H., Yau, C. Y., Schmitt, M. M., Schubert, I., Berggren, P. O., et al. (2014). TNF- $\alpha$ and IFN- $\gamma$ promote lymphocyte adhesion to endothelial junctional regions facilitating transendothelial migration. J. Leukoc. Biol. 95, 265-274. doi: 10.1189/jlb.0412205

Janco, M., Rynkiewicz, M. J., Li, L., Hook, J., Eiffe, E., Ghosh, A., et al. (2019). Molecular integration of the anti-tropomyosin compound ATM-3507 into the coiled coil overlap region of the cancer-associated Tpm3.1. Sci. Rep. 9:11262. doi: 10.1038/s41598-019-47592-9

Jiang, C., Fang, X., Jiang, Y., Shen, F., Hu, Z., Li, X., et al. (2016). TNF- $\alpha$ induces vascular endothelial cells apoptosis through overexpressing pregnancy induced noncoding RNA in Kawasaki disease model. Int. J. Biochem. Cell Biol. 72, 118-124. doi: 10.1016/j.biocel.2016.01.011

Kaczmarek, E., Erb, L., Koziak, K., Jarzyna, R., Wink, M. R., Guckelberger, O., et al. (2005). Modulation of endothelial cell migration by extracellular nucleotides: involvement of focal adhesion kinase and phosphatidylinositol 3kinase-mediated pathways. Thromb. Haemost. 93, 735-742. doi: 10.1160/TH0409-0576

Kasper, H. U., Schmidt, A., and Roessner, A. (1996). Expression of the adhesion molecules ICAM, VCAM, and ELAM in the arteriosclerotic plaque. Gen. Diagn. Pathol. 141, 289-294.

Krause, G., Winkler, L., Mueller, S. L., Haseloff, R. F., Piontek, J., and Blasig, I. E. (2008). Structure and function of claudins. Biochim. Biophys. Acta 1778, 631-645. doi: 10.1016/j.bbamem.2007

Libby, P. (2002). Inflammation in atherosclerosis. Nature 420, 868-874. doi: 10. 1038/nature 01323

Lu, Z. Y., Chen, W. C., Li, Y. H., Li, L., Zhang, H., Pang, Y., et al. (2016). TNF- $\alpha$ enhances vascular cell adhesion molecule-1 expression in human bone marrow mesenchymal stem cells via the NF-кB, ERK and JNK signaling pathways. Mol. Med. Rep. 14, 643-648. doi: 10.3892/mmr.2016.5314 
Ma, L., Li, Y., Peng, J., Wu, D., Zhao, X., Cui, Y., et al. (2015). Discovery of the migrasome, an organelle mediating release of cytoplasmic contents during cell migration. Cell Res. 25, 24-38. doi: 10.1038/cr.2014.135

Matsushita, H., Chang, E., Glassford, A. J., Cooke, J. P., Chiu, C. P., and Tsao, P. S. (2001). eNOS activity is reduced in senescent human endothelial cells: preservation by hTERT immortalization. Circ. Res. 89, 793-798. doi: 10.1161/ hh2101.098443

Michaelis, U. R. (2014). Mechanisms of endothelial cell migration. Cell. Mol. Life. Sci. 71, 4131-4148. doi: 10.1007/s00018-014-1678

Miyazaki, K., Hashimoto, K., Sato, M., Watanabe, M., Tomikawa, N., Kanno, S., et al. (2017). Establishment of a method for evaluating endothelial cell injury by TNF- $\alpha$ in vitro for clarifying the pathophysiology of virus-associated acute encephalopathy. Pediatr. Res. 81, 942-947. doi: 10.1038/pr.2017.28

Munro, J. M., Pober, J. S., and Cotran, R. S. (1989). Tumor necrosis factor and interferon-gamma induce distinct patterns of endothelial activation and associated leukocyte accumulation in skin of Papio anubis. Am. J. Pathol. 135, 121-133.

Ni, Y., Teng, T., Li, R., Simonyi, A., Sun, G. Y., and Lee, J. C. (2017). TNF $\alpha$ alters occludin and cerebral endothelial permeability: role of p38MAPK. PLoS One 12:e0170346. doi: 10.1371/journal.pone.0170346

O’Brien, K. D., McDonald, T. O., Chait, A., Allen, M. D., and Alpers, C. E. (1996). Neovascular expression of E-selectin, intercellular adhesion molecule-1, and vascular cell adhesion molecule-1 in human atherosclerosis and their relation to intimal leukocyte content. Circulation 93, 672-682. doi: 10.1161/01.cir.93.4.672

Ozawa, M., Hiver, S., Yamamoto, T., Shibata, T., Upadhyayula, S., Mimori-Kiyosue, Y., et al. (2020). Adherens junction regulates cryptic lamellipodia formation for epithelial cell migration. J. Cell Biol. 219:e202006196. doi: 10.1083/jcb. 202006196

Peppel, K., Zhang, L., Orman, E. S., Hagen, P. O., Amalfitano, A., Brian, L., et al. (2005). Activation of vascular smooth muscle cells by TNF and PDGF: overlapping and complementary signal transduction mechanisms. Cardiovasc. Res. 65, 674-682. doi: 10.1016/j.cardiores.2004

Perna, A. F., Sepe, I., Lanza, D., Capasso, R., Zappavigna, S., Capasso, G., et al. (2013). Hydrogen sulfide reduces cell adhesion and relevant inflammatory triggering by preventing ADAM17-dependent TNF- $\alpha$ activation. J. Cell Biochem. 114, 1536-1548. doi: 10.1002/jcb.24495

Perry, S. V. (2001). Vertebrate tropomyosin: distribution, properties and function. J. Muscle Res. Cell. Motil. 22, 5-49. doi: 10.1023/a:1010303732441

Qi, L., Jafari, N., Li, X., Chen, Z., Li, L., Hytönen, V. P., et al. (2016). Talin2mediated traction force drives matrix degradation and cell invasion. J. Cell Sci. 129, 3661-3674. doi: 10.1242/jcs.185959

Rastogi, S., Rizwani, W., Joshi, B., Kunigal, S., and Chellappan, S. P. (2012). TNF$\alpha$ response of vascular endothelial and vascular smooth muscle cells involve differential utilization of ASK1 kinase and p73. Cell Death Differ. 19, 274-283. doi: $10.1038 / \mathrm{cdd} .2011 .93$

Reglero-Real, N., Colom, B., Bodkin, J. V., and Nourshargh, S. (2016). Endothelial cell junctional adhesion molecules: role and regulation of expression in inflammation. Arterioscler. Thromb. Vasc. Biol. 36, 2048-2057. doi: 10.1161/ ATVBAHA.116.307610

Rosano, G. L., and Ceccarelli, E. A. (2014). Recombinant protein expression in Escherichia coli: advances and challenges. Front. Microbiol. 5:172. doi: 10.3389/ fmicb.2014.00172

Sainson, R. C., Johnston, D. A., Chu, H. C., Holderfield, M. T., Nakatsu, M. N., Crampton, S. P., et al. (2008). TNF primes endothelial cells for angiogenic sprouting by inducing a tip cell phenotype. Blood 111, 4997-5007. doi: 10.1182/ blood-2007-08-108597

Schevzov, G., Whittaker, S. P., Fath, T., Lin, J. J., and Gunning, P. W. (2011). Tropomyosin isoforms and reagents. Bioarchitecture 1, 135-164.

Semaan, H. B., Gurbel, P. A., Anderson, J. L., Muhlestein, J. B., Carlquist, J. F., Horne, B. D., et al. (2000). Soluble VCAM-1 and E-selectin, but not ICAM-1 discriminate endothelial injury in patients with documented coronary artery disease. Cardiology 93, 7-10. doi: 10.1159/000006995

Silvestre, J. S., Mallat, Z., Tedgui, A., and Lévy, B. I (2008). Post-ischaemic neovascularization and inflammation. Cardiovasc. Res. 78, 242-249. doi: 10. $1093 / \mathrm{cvr} / \mathrm{cvn} 027$

Smith, B. A., Daugherty-Clarke, K., Goode, B. L., and Gelles, J. (2013). Pathway of actin filament branch formation by Arp2/3 complex revealed by singlemolecule imaging. Proc. Natl. Acad. Sci. U.S.A. 110, 1285-1290. doi: 10.1073/ pnas. 1211164110
Smutny, M., Cox, H. L., Leerberg, J. M., Kovacs, E. M., Conti, M. A., Ferguson, C., et al. (2010). Myosin II isoforms identify distinct functional modules that support integrity of the epithelial zonula adherens. Nat. Cell Biol. 12, 696-702. doi: $10.1038 /$ ncb2072

Tavallaei, O., Bandehpour, M., Nafissi-Varcheh, N., and Kazemi, B. (2015). Periplasmic expression of TNF related apoptosis inducing ligand (TRAIL) in E.coli. Iran. J. Pharm. Res. 14, 617-626.

Theisen, U., Straube, E., and Straube, A. (2012). Directional persistence of migrating cells requires Kif1C-mediated stabilization of trailing adhesions. Dev. Cell 23, 1153-1166. doi: 10.1016/j.devcel.2012.11.005

Thomas, W. A., Boscher, C., Chu, Y. S., Cuvelier, D., Martinez-Rico, C., Seddiki, R., et al. (2013). $\alpha$-Catenin and vinculin cooperate to promote high E-cadherinbased adhesion strength. J. Biol. Chem. 288, 4957-4969. doi: 10.1074/jbc.M112. 403774

Tremblay, P. L., Auger, F. A., and Huot, J. (2006). Regulation of transendothelial migration of colon cancer cells by E-selectin-mediated activation of p38 and ERK MAP kinases. Oncogene 25, 6563-6573. doi: 10.1038/sj.onc.1209664

van Geemen, D., Smeets, M., van Stalborch, A.-M., Woerdeman, L., Daemen, M., Hordijk, P., et al. (2014). F-actin-anchored focal adhesions distinguish endothelial phenotypes of human arteries and veins. Arterioscler. Thromb. Vasc. Biol. 34, 2059-2067. doi: 10.1161/ATVBAHA.114.304180

Vicente-Manzanares, M., Ma, X., Adelstein, R. S., and Horwitz, A. R. (2009). Nonmuscle myosin II takes centre stage in cell adhesion and migration. Nat. Rev. Mol. Cell Biol. 10, 778-790. doi: 10.1038/nrm2786

Virdis, A., Ghiadoni, L., and Taddei, S. (2010). Human endothelial dysfunction: EDCFs. Pflugers Arch. 459, 1015-1023. doi: 10.1007/s00424-009-0783-7

Wang, J., Tang, C., Yang, C., Zheng, Q., and Hou, Y. (2019). Tropomyosin-1 functions as a tumor suppressor with respect to cell proliferation, angiogenesis and metastasis in renal cell carcinoma. J. Cancer 10, 2220-2228. doi: 10.7150/ jca. 28261

Wang, M., Li, W., Chang, G. Q., Ye, C. S., Ou, J. S., Li, X. X., et al. (2011). MicroRNA-21 regulates vascular smooth muscle cell function via targeting tropomyosin 1 in arteriosclerosis obliterans of lower extremities. Arterioscler. Thromb. Vasc. Biol. 31, 2044-2053. doi: 10.1161/ATVBAHA.111.229559

Woodfin, A., Voisin, M. B., Imhof, B. A., Dejana, E., Engelhardt, B., and Nourshargh, S. (2009). Endothelial cell activation leads to neutrophil transmigration as supported by the sequential roles of ICAM-2, JAMA, and PECAM-1. Blood 113, 6246-6257. doi: 10.1182/blood-2008-11-18 8375

Wu, H., Yao, Q., Lumsden, A., and Chen, C. (2004). Characterization of two populations of human coronary artery endothelial cells. J. Surg. Res. 118, 38-44. doi: 10.1016/j.jss.2004.01.009

Xue, F., Janzen, D. M., and Knecht, D. A. (2010). Contribution of filopodia to cell migration: a mechanical link between protrusion and contraction. Int. J. Cell Biol. 2010:507821. doi: 10.1155/2010/507821

Conflict of Interest: MG, DG, and AG are the authors on a patent disclosing the intravascular stent, especially for coronary vessels which inner covering comprises monoclonal anti-VE-cadherin antibodies and a system of induction of tropomyosin-1 expression.

The remaining authors declare that the research was conducted in the absence of any commercial or financial relationships that could be construed as a potential conflict of interest.

Publisher's Note: All claims expressed in this article are solely those of the authors and do not necessarily represent those of their affiliated organizations, or those of the publisher, the editors and the reviewers. Any product that may be evaluated in this article, or claim that may be made by its manufacturer, is not guaranteed or endorsed by the publisher.

Copyright (c) 2021 Gagat, Zielińska, Mikołajczyk, Zabrzyński, Krajewski, Klimaszewska-Wiśniewska, Grzanka and Grzanka. This is an open-access article distributed under the terms of the Creative Commons Attribution License (CC BY). The use, distribution or reproduction in other forums is permitted, provided the original author(s) and the copyright owner(s) are credited and that the original publication in this journal is cited, in accordance with accepted academic practice. No use, distribution or reproduction is permitted which does not comply with these terms. 